A Comprehensive Neutron Cross-Section and Secondary Energy Distribution Uncertainty Analysis for a Fusion Reactor

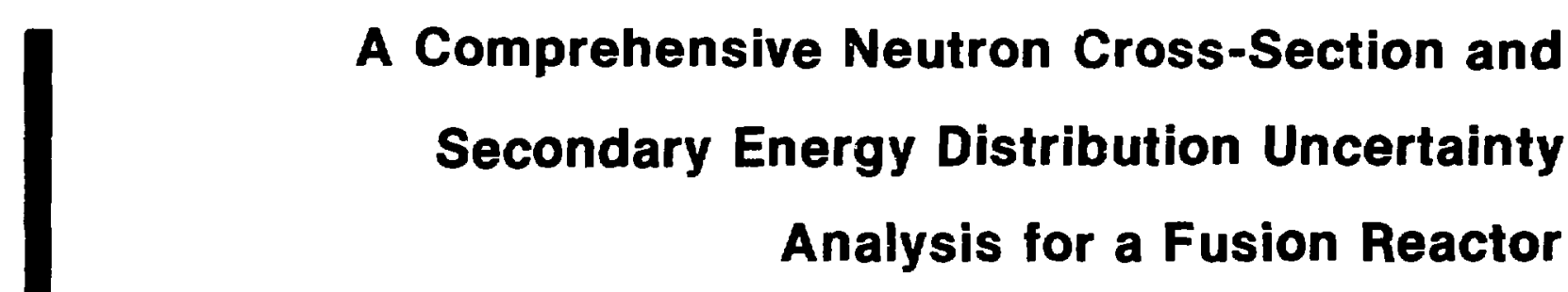




\section{A Comprehensive Neutron Cross-Section and Secondary Energy Distribution Uncertainty Analysis for a Fusion Reactor}

S. A. W. GerstI

R. J. LaBauve

P. G. Young
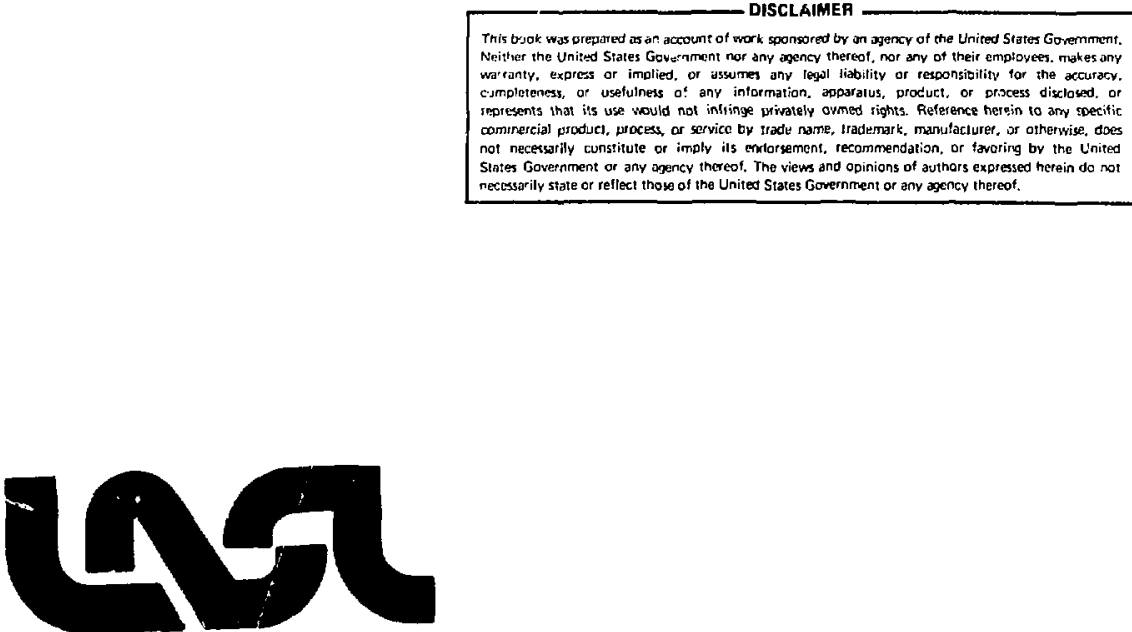


\section{CONTENTS}

ABSTRACT

I. INTRODUCTION . . . . . . . . . . . . . . . . . . . . . . 2

II. THEORY . . . . . . . . . . . . . . . . . . . . . . . . 2

III. CROSS-SECTION AND SECONDARY ENERGY DISTRIBUTION (SED) UNCERTAINTY DATA . 5 A. Cross-Section Covariance Data . . . . . . . . . . . . . . . 6

B. Secondary-Energy-Distribution Covariances . . . . . . . . . . . . 6

IV. NUCLEONICS ANALYSIS FOR GA'S TNS REACTOR CONCEPT (PGFR) . . . . . . . . . 9

V. QUANTITATIVE RESULTS . . . . . . . . . . . . . . . . . . . . . . . . . 11
A. Response Uncertainties caused by Reaction Cross-Section
Uncertainties . . . . . . . . . . . . . . . . . . . . . . 13
B. Response Uncertainties caused by SED Uncertainties . . . . . . . . .15
C. Total Response Uncertainties due to all Data Uncertainties . . . . . 15

VI. CONCLUSIONS AND RECOMMENDATIONS . . . . . . . . . . . . . . . . . . . 18

REFERENCES . . . . . . . . . . . . . . . . . . . . . . . . . . . . . 20

APPENDIX A . . . . . . . . . . . . . . . . . . . . . . . . . . . . . . . . . .

APPENDIX B . . . . . . . . . . . . . . . . . . . . . . . . . . . . . . . . . . . . 


\title{
A COMPREHENSIVE NEUTRON CROSS-SECTION AND SECONDARY ENERGY DISTRIBUTION UNCERTAINTY ANALYSIS FOR
}

\author{
A FUSION REACTOR
}

by

S. A. W. Gerstl

R. J. LaBauve

P. G. Young

ABSTRACT

On the example of General Atomic's well-documented Power Generating Fusion Reactor (PGFR) design, this report exercises $\bar{a}$ comprehensive neutron cross-section and secondary energy distribution (SED) uncertainty analysis. The LASL sensitivity and uncertainty analysis code SENSIT is used to calculate reaction cross-section sensitivity profiles and integral SED sensitivity coefficients. These are then folded with covariance matrices and integral SED uncertainties to obtain the resulting uncertainties of three calculated neutronics design parameters: two critical radiation damage rates and a nuclear heating rate. The report documents the first sensitivity-based data uncertainty analysis, which incorporates a quantitative treatment of the effects of SED uncertainties. The results demonstrate quantitatively that the ENDF/B-V cross-section data files for $C$, $H$, and 0 , including their SED data, are fully adequate for this design application, while the data for $\mathrm{Fe}$ and $\mathrm{Ni}$ are at best marginally adequate because they give rise to response uncertainties up to $25 \%$. Much higher response uncertainties are caused by cross-section and SED data uncertainties in $\mathrm{Cu}$ (26 to 45\%), tungsten ( 24 to $54 \%$ ), and $\mathrm{Cr}$ (up to $98 \%$ ). Specific recommendations are given for re-evaluations of certain reaction crosssections, secondary energy distributions, and uncertainty estimates. 


\section{INTRODUCTION}

One of the first steps in any new fusion reactor design is a neutronic analysis to determine adequate tritium breeding, nuclear heating in blankets and coils, acceptable radiation damage rates, etc. In an early phase it is usually sufficient to perform radiation transport calculations with a one-dimensional conceptual design model and allow for multi-dimensional streaming effects by estimated "streaming factors" which assure the 1-D model to be conservative. However, uncertainties in calculated neutronics design parametexs due to crosssection uncertainties will be present in both $1-\mathrm{D}$ as well a's multi-dimensional analyses. These latter uncertainties can be conveniently estimated by performing a cross-section sensitivity and uncertainty analysis ${ }^{(1)}$ based on the one-dimensional model.

Such quantitative data assessments have been performed in the past for various different fusion reactor designs, cf. e.g. Refs. (1) through (3). However, none of these analyses considers the effects of all nuclear data uncertainties simultaneously. Specifically, the effects of uncertainties in secondary energy and angular distributions have not been incorporated in the past, primarily due to the lack of a consistent methodology and the lack of uncertainty data for secondary distributions. Only recently such methodology has been developed ${ }^{(4)}$ and relevant uncertainty data are being made available.

This uncertainty analysis includes the effects of uncertainties in all neutron reaction cross-sections relevant to the model, including correlations, and the effects of estimated uncertainties in the neutron secondary energy distributions (SED's). Effects of uncertainties in secondary angular distributions are not incorporated for the lack of uncertainty data. Also, any uncertainties in gamma ray cross sections are neglected for two reasons: (1) generally, gamma ray interaction cross-sections are known to a much higher degree of accuracy (at least an order of magnitude) than neutron interaction cross-sections, and (2) only one of the three critical nuclear design parameters in our design depends at all on the gamma ray distribution.

\section{THEORY}

The theoretical expressions underlying any sensitivity-based cross-section uncertainty analysis have been developed previously, cf. e.g. Refs. (1) and (2), 
and are given here only for completeness. The variance of any calculated integral design parameter $R_{k}$ due to correlated uncertainties in given multigroup cross-section sets $\left\{\Sigma_{i}^{g}\right\}$ and $\left\{\Sigma_{j}^{g}\right\}$ can be calculated from

$$
\left(\frac{\Delta R_{k}}{R_{k}}\right)_{i, j}^{2}=\sum_{g, g^{\prime}} P_{i, k}^{g} P_{j, k}^{g^{\prime}} \operatorname{Cov}\left(\Sigma_{i}^{g}, \Sigma_{j}^{g^{\prime}}\right),
$$

where

$$
\begin{aligned}
\Sigma_{i}^{g}= & \text { neutron interaction cross-section for reaction } i \text { in energy } \\
& \text { group } g, \\
\operatorname{Cov}\left(\Sigma_{i}^{g}, \Sigma_{j}^{g^{\prime}}\right)= & \text { relative covariance matrix element for the multigroun cross- } \\
& \text { sections } \Sigma_{i}^{g} \text { and } \Sigma_{j}^{g}, \\
\mathrm{P}_{i, k}^{g} & \text { cross-section sensitivity profile for } \Sigma_{i}^{g} \text { with respect to } \\
& \text { the integral response } \mathrm{R}_{k} .
\end{aligned}
$$

All cross-section uncertainty information about reaction cross-sections is contained in the relative covariance matrix which is independent of the specific reactor design. All sensitivity information about reaction cross-sections enters Eq. (1) through the product of the sensitivity profiles which, of course, are highly problem-dependent and specific for a particular reactor design and for the particular design parameter considered 1 .

If the total response uncertainty due to many cross-section uncertainties is desired, then the relative standard deviation of the response $R_{k}$ due to all reaction cross-section uncertainties considered for a particular material is given by

$$
\left(\frac{\Delta R_{k}}{R_{k}}\right)_{M A T-X S}=\left(\sum_{i, j}\left(\frac{\Delta R_{k}}{R_{k}}\right)_{i, j}^{2}\right)^{\frac{1}{2}}
$$


assuming that the variances due to individual (partial) cross-section uncertainties are uncorrelated.

The theory for the consistent incorporation of the effects of uncertainties in secondary energy distributions (SED's) has only recently been developed ${ }^{(5)}$. The concept of hot/cold integral SED-sensitivities, which requires the specification of ntegral SED-uncertainty parameters, is adopted and applied here. As derived in Ref. 5, the relative standard deviation of an integral response $R_{k}$ due to SED-uncertainties for a specific reaction, $\ell$, that generates secondaries, is given by

$$
\left(\frac{\Delta R_{k}}{R_{k}}\right)_{\ell}=\sum_{g^{\prime}}\left|S_{\ell, g^{\prime}}^{S E n}\right| \cdot f_{\ell, g^{\prime}},
$$

where

$$
\begin{aligned}
\mathrm{f}_{\ell, g^{\prime}}= & \text { integral SED-uncertainty for neutron interaction } \ell \text { at the in- } \\
& \text { cident energy group } \mathrm{g}^{\prime} ; \mathrm{f} \text { is also called the spectral shape } \\
& \text { uncertainty parameter, } \\
\mathrm{S}_{\ell, g^{\prime}=}^{\mathrm{SED}} & \text { integral SED-sensitivity for the neutron interaction } \ell \\
& \text { at the incident energy group } \mathrm{g}^{\prime} .
\end{aligned}
$$

As noted in Ref. 5 the integral SED-sensitivity may be positive or negative, indicating whether the response $R_{k}$ is more sensitive to the hot portion of the SED or its cold part:

$$
S^{S E D}=S_{H O T}^{S E D}-S_{\text {COLD }}^{S E D}
$$

where the hot and cold portions of the integral SED-sensitivity are defined with respect to the median energy of the secondary distribution, cf. Ref. 5.

Equation (3) is valid for the sum of all SED-uncertainties pertaining to a single type of neutron interaction, identified by the subscript $\ell$. If the effects of SED-uncertainties from all possible neutron interactions with one material are to be considered, then we may assume that their effects on the responses $R_{k}$ are 
uncorrelated. With this assumption, the relative standard deviation of the response $R_{k}$ due to all SED-uncertainties considered for a particular material is given by

$$
\left(\frac{\Delta \mathrm{R}_{\mathrm{k}}}{\mathrm{R}_{\mathrm{k}}}\right)_{\text {MAT-SED }}=\left(\sum_{\ell}\left(\frac{\Delta \mathrm{R}_{\mathrm{k}}}{\mathrm{R}_{\mathrm{k}}}\right)_{\ell}^{2}\right)^{\frac{1}{2}} .
$$

Under the same assumption of independent, and therefore uncorrelated, effects on $R_{k}$ due to both all SED uncertainties and all reaction cross-section uncertainties per material, the total relative standard deviation of $R_{k}$ per material is given by

$$
\left(\frac{\Delta R_{k}}{R_{k}}\right)_{\text {MAT }}=\sqrt{\left(\frac{\Delta R_{k}}{R_{k}}\right)_{\text {MAT-XS }}^{2}+\left(\frac{\Delta R_{k}}{R_{k}}\right)_{\text {MAT-SED }}^{2}},
$$

which results from the quadratic sum of Eqs. (2) and (5). However, before any of the relative standard deviations defined in Eqs. (2), (3), (5), and (6) may be evaluated quantitatively, the data uncertainties in the form of covariance matrices and integral SED uncertainties, as well as the sensitivity profiles and integral SED-sensitivities must be quantified. In section III we describe how the required data uncertainties were obtained. In order to obtain the required sensitivity information a complete neutronics design analysis of the reactor system must be performed which is described in section IV.

III. CROSS-SECTION AND SECONDARY ENERGY DISTRIBUTION (SED) UNCERTAINTY DATA

One of the more important aspects of nuclear data is that the uncertainties tend to be highly correlated through the measurement processes and the corrections made to the observable quantities to obtain the microscopic cross sections. In many applications, the correlations of the uncertainties in the nuclear data play a crucial role in uncertainties in calculated results. 


\section{A. Cross-Section Covariance Data}

Several versions of the reference cross-section data library known as ENDF/ B (Evaluated Neutron Data Files-B) have been issued over the past 13 years, but only the latest version, ENDF/B-V, contains formats ${ }^{14}$ and sufficient covariance data for an application such as is described in this report. Covariance data are given for 25 important nuclides in ENDF/B-V, which includes data for all nuclides needed in this analysis except $\mathrm{Cu}$ and $\mathrm{W}$. For these elements we used the covariance files from $\mathrm{Fe}$ and $\mathrm{Pb}$, respectively, assuming that the cross sections of $\mathrm{Cu}$ are as well known as those for $\mathrm{Fe}$ and the cross sections of $W$ are as well known as those of $\mathrm{Pb}$. Note that both these assumptions are probably optimistic. It is planned, however, that covariance data for $\mathrm{Cu}$ and $W$ will be included in ENDF in the future, and the present calculations will be repeated when such data become available.

The covariance data in ENDF/B-V were processed with the NJOY code ${ }^{15}$ to transform the data into the 30-group multigroup format needed in this study. Data from the various runs with the NJOY code were collected to form a 30-group covariance data library. The contents of this library, which is in an ENDF-like format, are shown in Table I.

\section{B. Secondary-Energy-Distribution Covariances}

It should be noted that ENDF/B-V does not contain data uncertainties and their correlations for secondary energy distribution (SED) data, and at the time of this writing, formats have yet to be specified. Hence, for the purpose of estimating the magnitude of these effects, we have generated SED covariance matrices using the very simple "hot-cold" concept outlined in Ref. 5.

The angle-averaged median energies of the composite elastic plus nonelastic neutron emission spectra were calculated for each material as functions of incident neutron energy. Relative errors were then estimated for the portions of the emission spectra lying above and below the median energies. If $\bar{\sigma}$ designates the integrated neutron emission cross section $f^{\prime} r$ a given incident energy and $\sigma_{H}=$ $\bar{\sigma} / 2$ is the integrated spectrum for $E^{\prime}>E_{\text {median' }}^{\prime}$ then the relative uncertainties of the hot (denoted by subscript " $\mathrm{H}$ ") and cold (subscript "C") regions can be specified by the quantity $f=\Delta \sigma_{\mathrm{H}} / \bar{\sigma}=-\Delta \sigma_{\mathrm{C}} / \bar{\sigma}$. For the purposes of this study, we have assumed no correlation in the SED uncertainties with incident neutron energy.

Table II lists the median energies and the relative errors assumed in the 
TABLE I

ENDF/B-V COVARIANCE DATA (MF=33) PROCESSED WITH NJOY CODE

MA

$\begin{array}{llll}1301 & \mathrm{H}-1 & 16 & 1,2 \\ 1305 & \mathrm{~B}-10 & 17 & 1,2,107,780,781 \\ & & & \\ 1306 & \mathrm{C} & 18 & \begin{array}{l}1,2,4,51-68,91,102, \\ 104,107\end{array}\end{array}$

$1324 \mathrm{Cr}$

19

$1326 \mathrm{Fe}$

20

$1328 \quad \mathrm{~N} 1$

21

$1326 \mathrm{Cu}(\mathrm{Fe}) \quad 20$

$1382 \mathrm{~W}(\mathrm{~Pb}) \quad 22$ $91,102,103,104,107$.
Reaction Cross Sections

Total, elastic

Total, elastic, $(n, \alpha),\left(n, \alpha_{0}\right)$, and $\left(n, \alpha_{1}\right)$

Total, elastic, toal inelastic, inelastic levels $1-18$, inelastic continuum, $(n, \gamma),(n, d),(n, \alpha)$

$1,2,3,4,16,17,22,28$, Total, elastic, nonelastic, total $102,103,104,105,106$ inelastic, $(n, 2 n),(n, 3 n),\left(n, n^{\prime} \alpha\right)$, $\left(n, n^{\prime} p\right),(n, \gamma),(n, p),(n, t),(n, d)$, $\left(n,{ }^{3} \mathrm{He}\right),(n, \alpha)$

$1,2,3,4,16,22,28,102$, Tota1, elastic, nonelastic, tota1 $103,104,105,106,107$ Inelastic, $(n, 2 n),\left(n, n^{\prime} \alpha\right),\left(n, n^{\prime} p\right)$, $(n, \gamma),(n, p),(n, d),(n, t),\left(n,{ }^{3} H e\right)$, $(n, \alpha)$

$1,2,4,16,22,28,51-76$, Total, elastic, total inelastic, $(n, 2 n),\left(n, n^{\prime} \alpha\right),\left(n, n^{\prime} p\right)$, inelastic levels 1-26, inelastic continuum, $(n, \gamma),(n, p),(n, d),(n, \alpha),(n, 2 p)$

$1,2,3,4,16,17,22,28$, Total, elastic, nonelastic, total $102,103,104,106,107$ Inelastic, $(n, 2 n),(n, 3 n),\left(n, n^{\prime} \alpha\right)$, $\left(n, n^{\prime} p\right),(n, \gamma),(n, p),(n, d),(n, 3)$, $(n, \alpha)$

$1,2,3,4,16,17,51,52$, 64,102
Total, elastic, nonelastic, total Inelastic, $(n, 2 n),(n, 3 n)$, Inelastic levels 1,2 , and $14,(n, \gamma)$ 
TABLE II

MEDIAN ENERGIES ( $E_{M}^{\prime}$, IN MEV) AND FRACTIONAL UNCERTAINTIES (F) FOR SECONDARY ENERGY DISTRIBUTIONS AT INCIDENT NEUTRON ENERGIES $\mathrm{E}_{0}$

\begin{tabular}{|c|c|c|c|c|c|c|c|c|c|c|c|c|c|c|}
\hline \multirow[b]{2}{*}{$\mathrm{E}_{\mathrm{O}}$} & \multicolumn{2}{|l|}{${ }^{12} \mathrm{C}$} & \multicolumn{2}{|c|}{${ }^{16} 0$} & \multicolumn{2}{|c|}{$\mathrm{Cr}$} & \multicolumn{2}{|l|}{$\mathrm{Fe}$} & \multicolumn{2}{|l|}{$\mathrm{Ni}$} & \multicolumn{2}{|c|}{$\mathrm{Cu}$} & \\
\hline & $\mathrm{E}_{\mathrm{m}}^{\prime}$ & $\mathrm{F}$ & $\mathrm{E}_{\mathrm{m}}^{\mathrm{t}}$ & $\mathrm{F}$ & $\mathrm{E}_{\mathrm{m}}^{\prime}$ & $\mathrm{F}$ & $\mathrm{E}_{\mathrm{m}}^{\mathrm{t}}$ & $\mathrm{F}$ & $\mathrm{E}_{\mathrm{m}}^{\prime}$ & $\mathrm{F}$ & $\mathrm{E}_{\mathrm{m}}^{\prime}$ & $\mathrm{F}$ & $\mathrm{E}_{\mathrm{m}}^{\prime}$ & $F$ \\
\hline 16.0 & 14.71 & 0.071 & 14.62 & 0.088 & 3.27 & 0.17 & 4.49 & 0.11 & 14.95 & 0.13 & 3.42 & 0.11 & 1.86 & 0.12 \\
\hline 14.25 & 13.00 & 0.059 & 13.33 & 0.072 & 8.65 & 0.15 & 5.99 & 0.10 & 13.97 & 0.11 & 3.51 & 0.10 & 2.17 & 0.10 \\
\hline 12.75 & 11.71 & 0.054 & 11.93 & 0.062 & 11.42 & 0.13 & 11.17 & 0.10 & 12.67 & 0 . & 4.30 & .10 & 1.91 & 0.10 \\
\hline 11.00 & 9.77 & 0.060 & 9.82 & 0.057 & 10.48 & 0.11 & 10.57 & 0.09 & 10.91 & 1.10 & 10.42 & 0.09 & 1.57 & 0.09 \\
\hline 8.90 & 7.35 & 0.048 & 7.90 & 0.050 & 8.79 & 0.09 & 8.77 & 0.08 & 8.85 & 0 . & 8.81 & 08 & 1.24 & 0.08 \\
\hline 6.93 & 5.96 & 0.035 & 6.04 & 0.030 & 6.83 & 0.08 & 6.86 & 0.07 & 6.88 & 0.08 & 6.86 & 0.07 & 6.66 & 0.07 \\
\hline 4.88 & 4.46 & 0.010 & 4.57 & 0.010 & 4.81 & 0.07 & 4.81 & 0.07 & 4.83 & 0.07 & 4.82 & 0.07 & 4.83 & 0.07 \\
\hline 3.27 & 2.63 & 0.010 & 3.09 & 0.010 & 3.21 & 0.06 & 3.21 & 0.06 & 3.24 & 0.06 & 3.22 & 0.06 & 3.25 & 0.06 \\
\hline 2.55 & 2.16 & 0.010 & 2.31 & 0.010 & 2.48 & 0.05 & 2.49 & 0.06 & 2.49 & 0.05 & 2.50 & 0.06 & 2.51 & 0.06 \\
\hline 1.99 & 1.73 & 0.005 & 1.79 & 0.010 & 1.93 & 0.04 & 1.93 & 0.06 & 1.94 & 0.04 & 1.94 & 0.06 & 1.96 & 0.05 \\
\hline 1.55 & 1.34 & 0.005 & 1.35 & 0.010 & 1.50 & 0.03 & 1.51 & 0.05 & 1.50 & 0.03 & 1.51 & 0.05 & 1.51 & 0.05 \\
\hline 1.09 & 0.95 & 0.005 & 0.94 & 0.010 & 1.05 & 0.02 & 1.06 & 0.03 & 1.06 & 0.02 & 1.06 & 0.03 & 1.06 & 0.05 \\
\hline 0.66 & 0.57 & 0.005 & 0.60 & 0.010 & 0.64 & 0.02 & 0.63 & 0.02 & & & 0.64 & 0.02 & 0.66 & 0.04 \\
\hline 0.40 & 0.35 & 0.005 & 0.34 & 0.010 & & & 0.39 & 0.02 & & & 0.39 & 0.02 & 0.38 & 0.03 \\
\hline 0.24 & 0.21 & 0.005 & 0.22 & 0.010 & & & & & & & 0.24 & 0.02 & 0.22 & 0.02 \\
\hline 0.13 & 0.12 & 0.005 & 0.12 & 0.010 & & & & & & & 0.12 & 0.02 & 0.12 & 0.01 \\
\hline
\end{tabular}


total neutron emission spectra for each of the elements present. The relative errors were determined by adding in quadrature separate error components due to elastic and nonelastic neutron reactions.

The elastic scattering components are based upon the evaluated errors given in the ENDF/B-V files for ${ }^{12} \mathrm{C},{ }^{16} \mathrm{O}$, and $\mathrm{Fe}$, and upon our estimates of these errors for the other materials. Typically, the elastic uncertainty is approximately $8 \%$ near $14 \mathrm{MeV}$ and gradually reduces to a few percent near the inelastic threshold. These errors are significantly smaller in the case of ${ }^{12} \mathrm{C}$, which is used as a standard in neutron scattering experiments.

The nonelastic neutron spectrum exrors were determined by combining quadratically a $15 \%$ component assumed to exist for all materials at all energies and a second component based on comparisons with the 14-MeV spectrum measurements of Hermsdorf et al ${ }^{23}$ and Clayeux and Voignier. ${ }^{24}$ This latter component was included to roughly account for variations in the accuracy of the individual evaluations. $\mathrm{Cnl}_{\mathrm{y}}$ in the cases of $\mathrm{Cr}$ and $\mathrm{Ni}$ did the addition of the second component significantly change the total SED uncertainty. It should be mentioned that significant differences also exist between the measured and calculated spectra for $W$, as has been shown by Hetrick et al. 25 In averaging over the "hot" (or "cold") portions of the $14-\mathrm{MeV}$ spectrum for $\mathrm{W}$, however, a significant fraction of this spectrum difference disappears. This cancellation indicates one of the problems inherent in using such a coarse representation of SED errors.

IV. NUCLEONICS ANALYSIS FOR GA'S TNS REACTOR CONCEPT (PGFR)

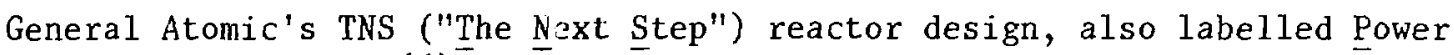
Generating Fusion Reactor ${ }^{(6)}$, has been selected as a representative model $t_{i} r$ all TNS reactor concepts; Fig. 1 shows a cut-away view of the PGFR. A nuclear analysis for this reactor has been performed by General Atomic (GA) and is documented in Ref. 7, which has been issued as Vol. IV of Ref. 6. In this analysis GA identifies as the three most critical nuclear design parameters (1) the radiation damage to the superconducting $\mathrm{TF}-\mathrm{coil}^{\prime} \mathrm{s}$ stabilizing matrix, (2) the radiation damage to the alumina insulator in the F-coil, and (3) the nuclear heating in the superconducting TF-coil. Two one-dimensional models have been employed in the GA nucleonic analysis, an inboard and an outkoard model. However, the inboard calculations were sufficient to identify the above three most critical parameters. Therefore, we selected for our data assessment task the PGFR inboard nucleonics 


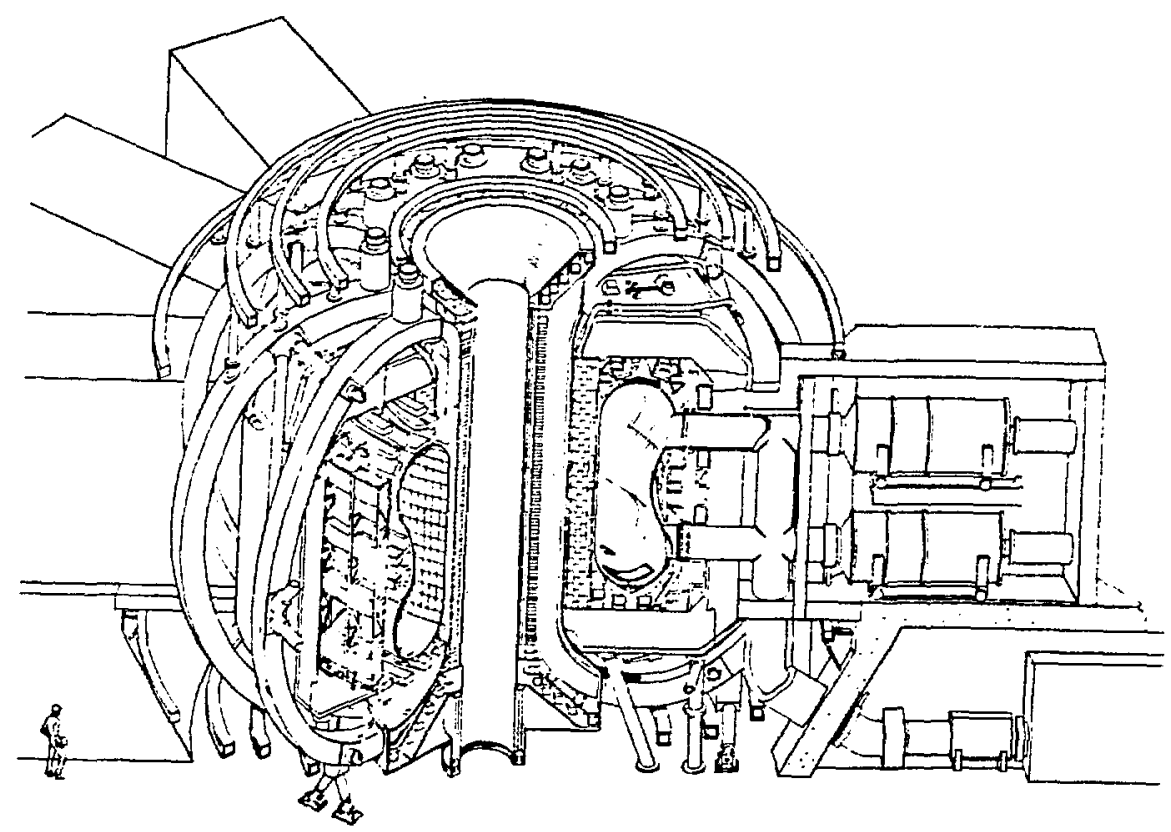

Fig. 1. General Atomic's Power Generating Fusion Reactor (PGFR)

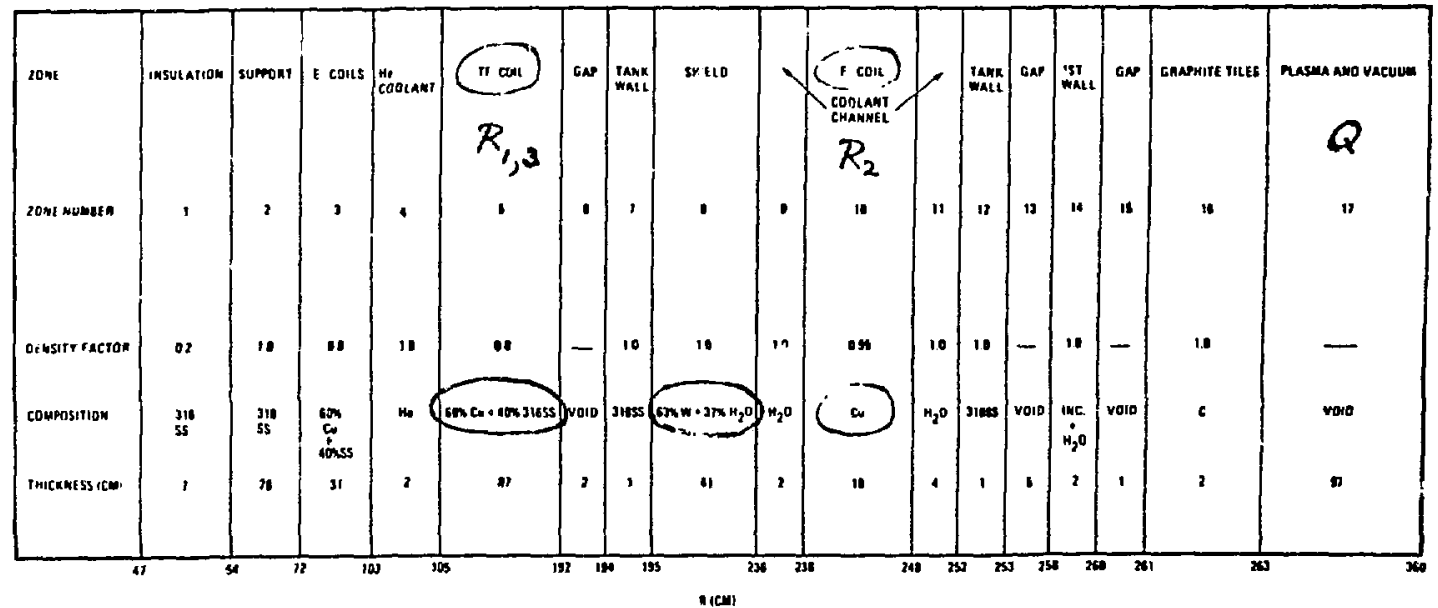

Fig. 2. PGFR inboard nucleonics model. 
model which is reproduced from Ref. 7 and shown in Fig. 2. The symbol Q represents the $14-\mathrm{MeV}$ neutron source at the plasma location while the $\mathrm{R}_{1,2,3}$ indicate the locations where the 3 critical responses are cailculated for which the following response functions were chosen:

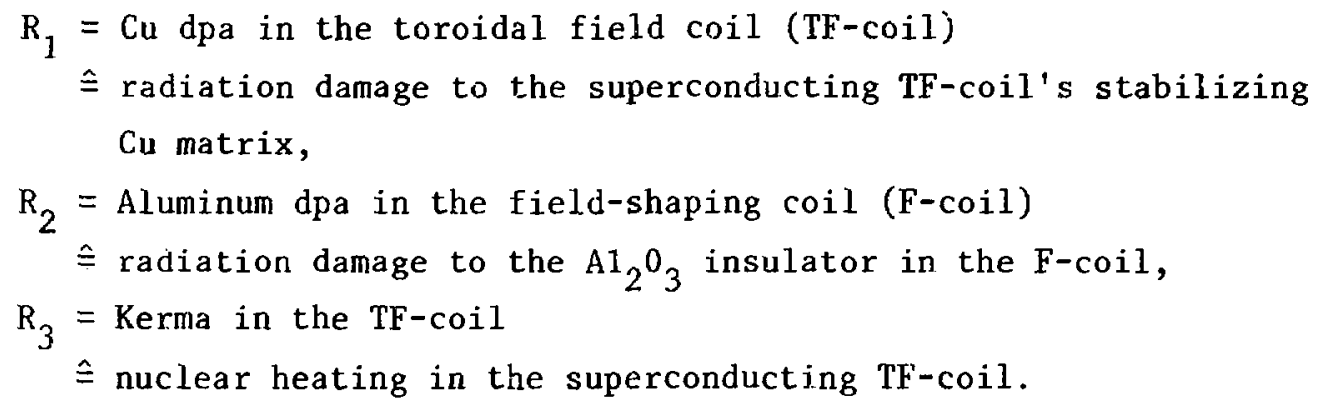

All data for the response functions as well as the multigroup cross-section sets used in the analysis, were derived from ENDF/B-V $(8,9)$ and processed with the NJOY code system $(10)$ into coupled neutron/gamma-ray multigroup sets with 30 neutron and 12 gamma-ray groups (11). The resulting multigroup data library has been applied successfully at LASL to several other fusion nucleonics analyses and is therefore considered a well tested and reliable cross-section data base.

The nuclear analysis of the PGFR was performed with the LASL discrete-ordinates code ONETRAN $(12)$ in $\mathrm{S}_{8}$ approximation and with $\mathrm{P}_{2}$ coupled neutron and gamma-ray cross-sections. The angular flux distributions from the forward ONETRAN run and the three adjoint runs (one for each of the above response functions) were then used in the LASL sensitivity and uncertainty analysis code SENSIT(13) to compute the relevant sensitivity profiles and response uncertainties.

\section{QUANTITATIVE RESULTS}

Uncertainties in the three critical design parameters $R_{1,2,3}$ were calculated with SENSIT in two independent stages. First the response uncertainties due to uncertainties in neutron reaction cross-sections were calculated via Eqs. (1) and (2), and then, in a second stage, the additional response uncertainties due to estimated SED uncertainties were computed via Eqs. (3) through (5). 
TABLE FOR DEFINITION OF ID-NOS IN TERMS OF SPECIFICATION OF CROSS SECTION COVAR IANCES. NOTE IN THIS VERSION, MATI =MATZ

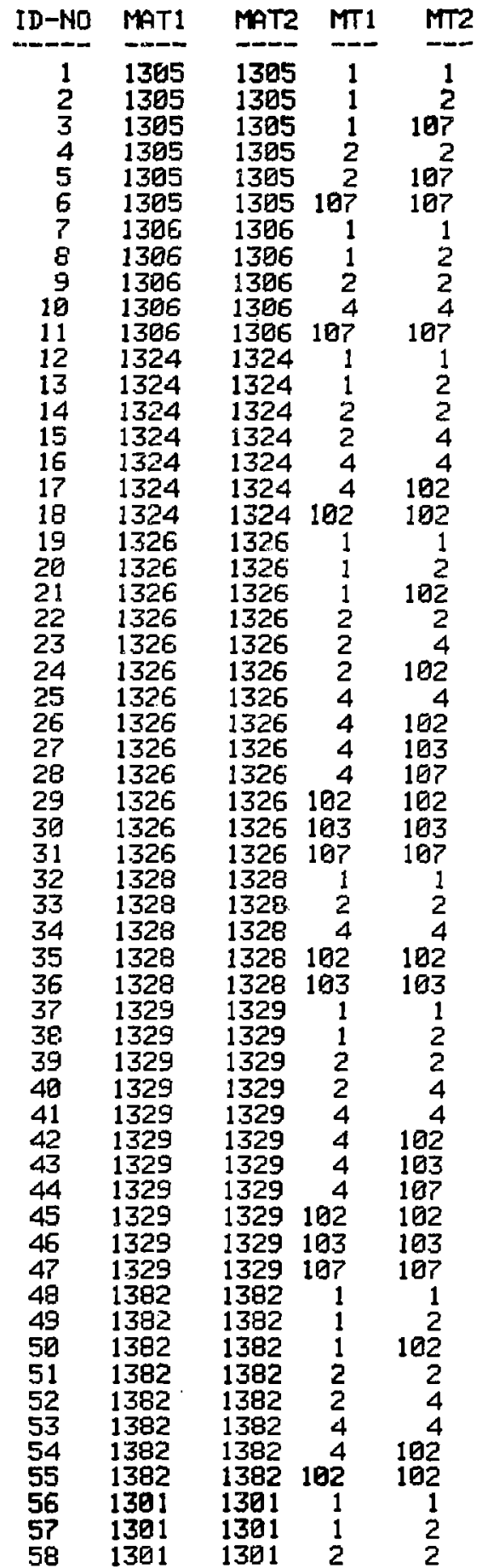

CROSS SECTION COVARIANCE

B10 TOTAL WITH B10 TOTA:
B10 TOTAL WITH B1D ELASTIC

BIO TOTAL WITH BID (N,ALPHA)

B10 ELASTIC WITH B1Q ELASTIC

B10 ELASTIC WITH B10 (N.ALPHA)

SiD (N.ALPHA) WITH B10 (N,ALPHA)

C TOTAL WITH C TOTAL

C TOTAL WITH C ELASTIC

C ELASTIC WITH C ELASTIC

C INELASTIC WITH C INELASTIC

C (N,ALPHA) WITH C (N,ALPHA)

CR TOTAL WITH CR TOTAL

CR TOTAL WITH CR ELASTIC

CR ELASTIC WITH CR ELASTIC

CR ELASTIC WITH CR INELASTIC

ER INELASTIC WITH CR INELASTIC

CR INELLASTIC WITH CR CAPTURE

CR CAPTURE WITH CR CAPTURE

FE TOTAL WITH FE TOTAL

FE TOTAL WITH FE ELASTIC

FE TOTAL WITH FE CAPTURE

FE ELASTIC WITH FE ELASTIC

FE ELASTIC WITH FE INELASTIC

FE ELASTIC WITH FE CAPTURE

FE INELASTIC WITH FE INELASTIC

FE INELASTIC WITH FE CAPTURE

FE INELASTIC WITH FE (N,P)

FE INELASTIC WITH FE (N.ALPHA)

FE CAPTURE WITH FE CAPTURE

FE (N,P) WITH FE (N,P)

FE ( $N, A L P H A)$ WITH FE (N, ALPHA)

NI TOTAL WITH NI TOTAL

NI ELASTTIC WITH NI ELASTIC

NI INELASTIC WITH NI INELASTIC

NI CAPTURE WITH NI CAPTURE

NI (N,P) WITH NI (N,P)

CU TOTAL WITH CU TOTAL

CU TOTAL WITH CU ELASTIC

CU ELASTIC WITH CU ELASTIC

CU ELASTIC WITH CU INELASTIC

CU INELASTIC WITH CU INELASTIC

CU INELASTIC WITH CU CAPTURE

CU INELASTIC WITH CU $(N, P)$

CU INELASTIC WITH CU (N,ALPHA)

CU CAPTURE WITH CU CAPTURE

CU (N.P) WITH CU (N.P)

CU (N.ALPHA) WITH CU (N.ALPHA)

PB TOTAL WITH PB TOTAL

PB TOTAL WITH PE ELASTIC

PB TOTAL WITH PB CAPTURE

PB ELASTIC WITH PB ELASTIC

PB ELASTIC WITH PB INELASTIC

$P B$ INELASTIC WITH PB INELASTIC

PB INELASTIC WITH PB CAPTURE

PB CAPTURE WITH PB CAPTURE

H TOTAL WITH H TOTAL

H TOTAL WITH H ELASTIC

H ELASTIC WITH H ELASTIC 
A. Response Uncertainties caused by Reaction Cross-Section Uncertainties

A total of 24 SENSIT runs were performed to compute $\Delta R_{k} / R_{k}$ cause by reaction cross-section uncertainties which are given as relative covariance matrices for pairs of partial reaction cross-sections. Table III gives a listing of these covariance matrices and identifies the relevant pairs of partial cross-sections by ID-numbers. Partial cross-sections for one material were only paired with partials for the same material because it is assumed that the cross-section uncertainties for one material are uncorrelated with those for another material.

However, certain mateiials are present in more than one spatial zone of the PGFR design; cf. Fig. 2. For example, chromium is present in the first wall, in all stainless steel structural walls and in the TF and $E$ coils, but with a different number density in each zone. Therefore, to simplify the interpretation of our results, we report contributions to response uncertainties due to crosssection uncertainties by material zones as defined by their operational function, like $\mathrm{Cr}$ in the first wall, or in all SS walls, or in all coil structures, etc. Appendix A gives detailed results of our cross-section uncertainty analysis for those response uncertainty components which exceed a $10 \%$ standard deviation. The sensitivity profiles for each of the two partial cross-sections of each pair are also given in these tables. A summary of all calculated response uncertainties due to all cross-section uncertainties is given in Table IV. All standard deviations in Table IV per material ( $i$ ) and zone ( $j$ ) are obtained by quadratically summing the standard deviations caused by all partial crosssections for that material according to Eq. (2). The overall response uncertainties for $R_{1,2,3}$ due to all reaction cross-section uncertainties are given in the bottom line of Table IV. Large standard deviations of $71.9 \%$ and $125.2 \%$ are predicted for the responses $R_{1}$ and $R_{3}$, respectively. In both cases the largest contributions originate from cross-section uncertainties in $\mathrm{Cr}, \mathrm{W}, \mathrm{Cu}$, and $\mathrm{Ni}$. However, due to the unavailability of evaluated cross-section uncertainty data for $\mathrm{Cu}$ and $\mathrm{W}$ we substituted the covariance data for these materials with those for $\mathrm{Fe}$ and $\mathrm{Pb}$, as was explained in Section IIIA. These substitutions are thought to be optimistic in the sense that the $\mathrm{Fe}$ and $\mathrm{Pb}$ covariances are probably generally smaller thin such data would be for Cu and $W$. Therefore, we feel these substitutions do not seriously weaken our conclusions that the $\mathrm{Cu}$ and $\mathrm{W}$ cross section data are serious sources of uncertainty in the $R_{1}$ and $R_{3}$ responses. 
TABLE IV

PREDICTED RESPONSE UNCERTAINTIES (STANDARD DEVIATION) DUE TO ESTIMATED CROSS-SECTION UNCERTAINTIES

\begin{tabular}{|c|c|c|c|c|c|c|c|}
\hline \multicolumn{2}{|c|}{ CROSS SECT. } & \multicolumn{6}{|c|}{ Response Uncertainties, in percent } \\
\hline $\begin{array}{l}\text { MAT. } \\
\text { (i) }\end{array}$ & $\begin{array}{c}\text { ZONE } \\
(j)\end{array}$ & $\left(\frac{\Delta \mathrm{R}_{1}}{\mathrm{R}_{1}}\right)_{\mathrm{i}, \mathrm{j}}^{100}$ & $\left(\frac{\Delta R_{1}}{R_{1}}\right)_{i}^{*}$ & $\left(\frac{\Delta R_{2}}{R_{2}}\right)_{i, j}^{100 x}$ & $\left(\frac{\Delta \mathrm{R}_{2}}{\mathrm{R}_{2}}\right)_{\mathrm{i}}^{*}$ & $\left(\frac{\Delta R_{3}}{R_{3}}\right)_{i, j}^{10}$ & $\left(\frac{\Delta R_{3}}{R_{3}}\right)_{i}^{*}$ \\
\hline C & TILES & 1.69 & 1.69 & 2.05 & 2.05 & 1.70 & 1.70 \\
\hline $\mathrm{Cr}$ & $\begin{array}{l}\text { FIRST WALL } \\
\text { SS WALLS } \\
\text { TF+E COILS }\end{array}$ & $\begin{array}{l}0.38 \\
0.13 \\
28.7 \\
\end{array}$ & 28.7 & $\begin{array}{l}0.47 \\
0.04 \\
6 \times 10^{-10} \\
\end{array}$ & 0.47 & $\begin{array}{l}0.38 \\
5.3 \\
98.2 \\
\end{array}$ & 98.3 \\
\hline $\mathrm{Ni}$ & $\begin{array}{l}\text { FIRST WALL } \\
\text { SS WALLS } \\
\text { TF+E COILS }\end{array}$ & $\begin{array}{l}1.79 \\
1.81 \\
6.43 \\
\end{array}$ & 6.91 & $\begin{array}{l}2.21 \\
0.78 \\
9 \times 10^{-9} \\
\end{array}$ & 2.34 & $\begin{array}{l}1.79 \\
1.5 \\
24.8 \\
\end{array}$ & 24.9 \\
\hline $\mathrm{Fe}$ & $\begin{array}{l}\text { FIRST WALL } \\
\text { SS WALLS } \\
\text { TF+E COILS }\end{array}$ & $\begin{array}{l}0.18 \\
2.61 \\
13.9 \\
\end{array}$ & 14.1 & $\begin{array}{l}0.22 \\
1.67 \\
2 \times 10^{-8} \\
\end{array}$ & 1.68 & $\begin{array}{l}0.18 \\
2.46 \\
15.8 \\
\end{array}$ & 15.99 \\
\hline $\mathrm{Cu}$ & $\begin{array}{l}\mathrm{F}-\mathrm{COIL} \\
\mathrm{TF}+\mathrm{E} \text { COILS }\end{array}$ & $\begin{array}{r}3.68 \\
32.8 \\
\end{array}$ & 33.0 & $\begin{array}{l}4.80 \\
8 \times 10^{-9}\end{array}$ & 4.80 & $\begin{array}{l}3.66 \\
45.1 \\
\end{array}$ & 45.3 \\
\hline W & SHIELD & 54.0 & 54.0 & 0.196 & 0.196 & 54.3 & 54.3 \\
\hline H & $\begin{array}{l}\text { FIRST WALL } \\
\mathrm{H}_{2}{ }^{\prime} \text { CONLT. } \\
\text { SHIELD }\end{array}$ & $\begin{array}{l}0.07 \\
0.49 \\
5.72 \\
\end{array}$ & 5.74 & $\begin{array}{l}1.11 \\
0.76 \\
0.066 \\
\end{array}$ & 0.77 & $\begin{array}{l}0.073 \\
0.50 \\
8.7 \\
\end{array}$ & 8.71 \\
\hline 0 & $\begin{array}{l}\text { FIRST WALL } \\
\mathrm{H}_{2} \mathrm{O} \text { COOLT. } \\
\text { SHIELD }\end{array}$ & $\begin{array}{l}0.25 \\
1.51 \\
7.52 \\
\end{array}$ & 7.67 & $\begin{array}{l}0.28 \\
1.01 \\
0.014 \\
\end{array}$ & 1.05 & $\begin{array}{l}0.25 \\
1.50 \\
7.5 \\
\end{array}$ & 7.65 \\
\hline$L^{*}$ & & & 71.9 & & 6.12 & & 125.1 \\
\hline
\end{tabular}

*) quadratic sums 


\section{B. Response Uncertainties caused by SED Uncertainties}

In a second series of 24 computer runs with SENSIT (in SED anaylsis mode ITYP $=3)^{13}$, the additional response uncertainties $\Delta R_{k} / R_{k}$ due to estimated uncertainties in secondary energy distributions were evaluated according to Egs. (3) and (5). Integral SED uncertainties ${ }^{f} \ell, g$, between $0.5 \%$ and $17 \%$ were used as input, as specified in Table II, for incident neutron energies between 16 and $0.13 \mathrm{MeV}$.

Appendix B gives the detailed results of our SED uncertainty analysis for those calculated response uncertainties which exceed a $10 \%$ standard deviation. Integral SED-sensitivity coefficients $S^{S E D}$, together with $S_{H O T}^{S E D}$ and $S_{\text {COLD }}^{S E D}$ according to Eq. (4), are also given in Appendix B for each incident energy group. All calculated response uncertainties due to all SED uncertainties are summarized in Table $V$ by material ( $i$ ) and zone $(j)$. It should be noted that in this case no substitutions of cross-section or uncertainty files were performed as was necessary for the copper and tungsten reaction cross-section uncertainty analysis. The largest response uncertain ies due to SED uncertainties are calculated for $R_{1}(33.1 \%)$ and $R_{3}(37.1 \%)$ which are both mainly due to $C u$ and $W$ SED uncertainties, each contributing between 23 and $28 \%$ in $\Delta R / R$.

A note of caution must be added here, which should be taken into consideration when the results of this SED uncertainty analysis are interpreted. As mentioned in Section III.B, the integral SED uncertainties were estimated for the composite secondary energy distributions of elastic and nonelastic reactions, which resulted in the fairly low spectral shape uncertainty parameters $f_{\ell, g}$ listed in Table II. In addition, such composite SED's often exhibit two distinctly separated peaks, one due to the elastically scattered secondaries peaking fairly close to the incident neutron energy, and the second at much lower energies due to nonelastic emission neutrons. In these situations it is questionable how adequate the SED uncertainties can be realistically described by the simple hot/cold concept which is the basis for our anaylsis (5). Quite possibly this concept may result in too coarse a representation and may therefore underestimate the real response uncertainties due to SED uncertainties. This potential inadequacy could be remedied, however, if SED uncertainties were treated separately for individual partial cross-sections.

\section{Total Response Uncertainties due to all Data Uncertainties}

Summary Tables IV and $\mathrm{V}$ give the calculated response uncertainties by material as defined in Eqs. (2) and (5), respectively. In Table VI we compare the 
TABLE V

PREDICTED RESPONSE UNCERTAINTIES (STANDARD DEVIATION) DUE TO ESTIMATED SED UNCERTAINTIES

\begin{tabular}{|c|c|c|c|c|c|c|c|}
\hline \multicolumn{2}{|c|}{$\begin{array}{l}\text { CROSS SECT. } \\
\text { MAT. ZONE }\end{array}$} & \multicolumn{6}{|c|}{ Response Uncertainties, in percent } \\
\hline $\begin{array}{l}\text { MAT. } \\
\text { (i) }\end{array}$ & $\begin{array}{c}\text { ZONE } \\
(j)\end{array}$ & $\left(\frac{\Delta R_{1}}{R_{1}}\right)_{i, j}^{100 x}$ & $\left(\frac{\Delta R_{1}}{R_{1}}\right)_{i}$ & $\left(\frac{\Delta R_{2}}{R_{2}}\right)_{i, j}^{100 x}$ & $\left(\frac{\Delta R_{2}}{R_{2}}\right)_{i}^{i}$ & $\left(\frac{\Delta R_{3}}{R_{3}}\right)_{i, j}^{100}$ & $\left(\frac{\Delta R_{3}}{R_{3}}\right)_{i}^{*}$ \\
\hline $\mathrm{C}$ & TILES & 0.41 & 0.41 & 0.26 & 0.26 & 0.41 & 0.41 \\
\hline $\mathrm{Cr}$ & $\begin{array}{l}\text { FIRST WALL } \\
\text { SS WALLS } \\
\text { TF+E COILS }\end{array}$ & $\begin{array}{l}0.24 \\
0.33 \\
1.10 \\
\end{array}$ & 1.17 & $\begin{array}{l}0.27 \\
0.23 \\
2 \times 10^{-10}\end{array}$ & 0.35 & $\begin{array}{l}0.24 \\
0.31 \\
0.76 \\
\end{array}$ & 0.86 \\
\hline $\mathrm{Ni}$ & $\begin{array}{l}\text { FIRST WALL } \\
\text { SS WALLS } \\
\text { TF+E COILS }\end{array}$ & $\begin{array}{l}0.79 \\
0.31 \\
0.31 \\
\end{array}$ & 0.86 & $\begin{array}{l}0.74 \\
0.08 \\
1 \times 10^{-10}\end{array}$ & 0.75 & $\begin{array}{l}0.79 \\
0.13 \\
0.28 \\
\end{array}$ & 0.85 \\
\hline $\mathrm{Fe}$ & $\begin{array}{l}\text { FIRST WALL } \\
\text { SS WALLS } \\
\text { TF+E COILS }\end{array}$ & $\begin{array}{l}0.06 \\
0.94 \\
6.50 \\
\end{array}$ & 6.57 & $\begin{array}{l}0.07 \\
0.51 \\
6 \times 10^{-10} \\
\end{array}$ & 0.52 & $\begin{array}{l}0.06 \\
0.84 \\
4.50 \\
\end{array}$ & 4.58 \\
\hline $\mathrm{Cu}$ & $\begin{array}{l}\mathrm{F}-\mathrm{COIL} \\
\mathrm{TF}+\mathrm{E} \text { COILS }\end{array}$ & $\begin{array}{l}5.2 \\
25.6 \\
\end{array}$ & 26.1 & $\begin{array}{l}10.1 \\
1 \times 10^{-9} \\
\end{array}$ & 10.1 & $\begin{array}{l}5.2 \\
27.5 \\
\end{array}$ & 28.0 \\
\hline W & SHIELD & 23.5 & 23.5 & 0.37 & 0.37 & 23.9 & 23.9 \\
\hline H & $\begin{array}{l}\text { FIRST WAIL } \\
\mathrm{H}_{2} \mathrm{O} \text { COOLT. } \\
\text { SHIELD }\end{array}$ & $\begin{array}{l}0.10 \\
0.39 \\
0.90 \\
\end{array}$ & 0.99 & $\begin{array}{l}0.07 \\
0.36 \\
0.01 \\
\end{array}$ & 0.37 & $\begin{array}{l}0.09 \\
0.39 \\
0.95 \\
\end{array}$ & 1.03 \\
\hline 0 & $\begin{array}{l}\text { FIRST WALL } \\
\mathrm{H}_{2} \mathrm{O} \text { COOLT. } \\
\text { SHIELD }\end{array}$ & $\begin{array}{l}0.11 \\
0.45 \\
0.94 \\
\end{array}$ & 1.05 & $\begin{array}{l}0.10 \\
0.46 \\
0.02 \\
\end{array}$ & 0.47 & $\begin{array}{l}0.11 \\
0.46 \\
1.03 \\
\end{array}$ & 1.13 \\
\hline$A L L *$ & & & 33.1 & & 10.2 & & 37.1 \\
\hline
\end{tabular}

*) quadratic sums 
TABLE VI

TOTAL RESPONSE UNCERTAINTIES (STANDARD DEVIATION) DUE TO ALL DATA UNCERTAINTIES

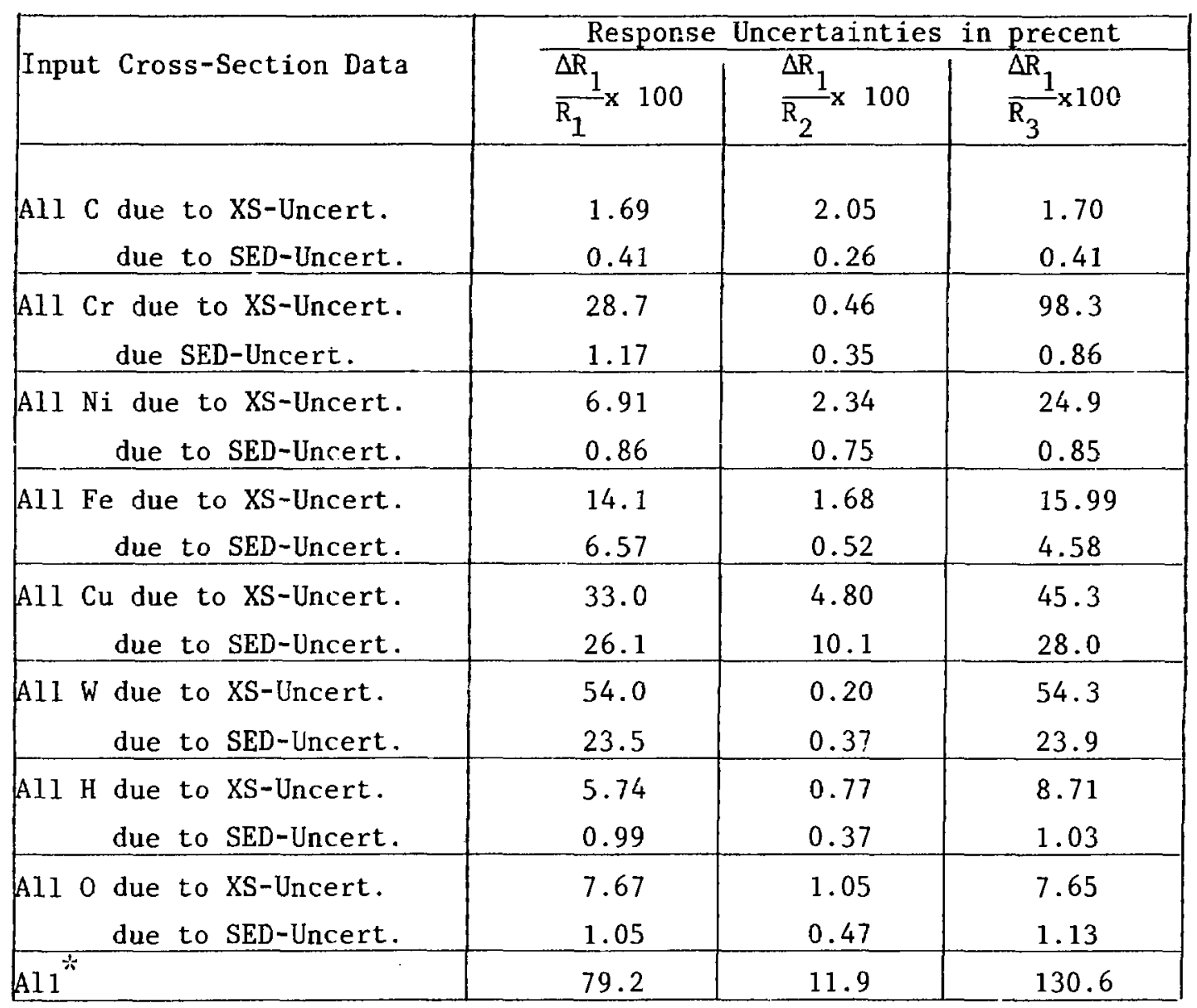

*) quadratic sums 
calculated response uncertainties due to cross-section uncertainties with those due to SED uncertainties per material. We note that in almost all cases the response uncertainties due to SED uncertainties are smaller than those due to reaction cross-section uncertainties.

The total response uncertainties due to all data uncertainties were calculated using Eq. (6), which assumes all individual results summarized in Table VI are uncorrelated and may be summed quadratically by column. The large total response uncertainties of $79 \%$ for $R_{1}$ and $130 \%$ for $R_{3}$ are reasons for concern in a real design environment. In our conclusion we recommend, therefore, that certain cross-section files including the SED data, and certain covariance files, be reevaluated. However, if such re-evaluations or re-measurements siould result in only insignificantly lower response uncertainties, then some additional conservatism might have to be built into future blanket and shield designs.

VI. CONCLUSIONS AND RECOMMENDATIONS

In general, when a cross-section uncertainty analysis is performed with presently available codes and data, some care must be taken in the interpretation of the results. Specifically, it must be recognized that considerable uncertainty generally exists in the covariance files with the result that fairly large errors are possible in the calculated response lncertainties themselves. Additionally, any conclusions regarding the adequacy of nuclear data for a particular application requires a statement as to what errors are tolerable in the calculated responses. For the conclusions below we have assumed that response uncertainties greater than $\sim 25 \%$ are not acceptable.

With these qualifications in mind, the main conclusions drawn from this PGFR cross-section and SED uncertainty analysis are the following:

1. The quadratic combination of the worst case response uncertainties $\left(R_{3}\right)$ for $\mathrm{H}, \mathrm{C}$, and 0 results in a combined uncertainty of less than $13 \%$. Therefore, the existing ENDF/B- $V$ neutron cross-section files for these materials, including SED data, appear to be fully adequate for this application.

2. The calculated $\mathrm{R}_{3}$ response uncertainties for $\mathrm{Ni}$ and $\mathrm{Fe}$ are $25 \%$ and $17 \%$, respectively, with the major components resulting from cross-section 
uncertainties. The data for these materials therefore appear to be marginally adequate for the present application, although some further reduction in uncertainty would probably be desirable.

3. The $W$ cross-section data are probably inadequate, as indicated by a calculated response uncertainty of $54 \%$ for both $R_{1}$ and $R_{3}$. This conclusion must be qualified somewhat because $P b$ covariance data were used in the $\mathrm{W}$ analysis. However, an examination of the $\mathrm{Pb}$ covariance file suggests strongly that this qualitative conclusion would stand even if $W$ covariances were available. Additionally, the calculated $24 \%$ response uncertainties in $R_{1}$ and $R_{3}$ due to tungsten SED uncertainties alone indicate a need for improved data. It is recommended, therefore, that as a first step the cross-section and uncertainty files for $W$ be re-evaluated to include the most recent experimental results.

4. For $\mathrm{Cu}$ the cross-section as well as the SED data appear inadequate because they produce respunse uncertainties in $R_{1}$ and $R_{3}$ between 26 and $45 \%$. Specifically, large sensitivities are obtained for the elastic and total copper cross-sections (see Appendix A) and SED's (see Appendix B) in the energy range from $1.3 \mathrm{keV}$ to $1.3 \mathrm{MeV}$. These cross-sections and secondary energy distributions are recommended for re-evaluation and possibly re-measurement. Again, these conclusions are subject to a similar qualification as was given for the $W$ results in that $\mathrm{Fe}$ covariance data were used in the absense of such data for $\mathrm{Cu}$. As with tungsten, however, we believe the qualitative conclusions for $\mathrm{Cu}$ are valid.

5. The cross-section data for $\mathrm{Cr}$ appear grossly inadequate because they produce an almost $100 \%$ uncertainty in $\mathrm{R}_{3}$, while the SED data are found fully adequate. The main contribution to the $98 \%$ standard deviation is from the $\mathrm{Cr}$ total and elastic cross-sections (compare Appendix A). While the sensitivity of $R_{3}$ to the $\mathrm{Cr}$ total and elastic cross-sections is roughly a factor of 10 lower than the sensitivity of $R_{3}$ to the copper cross-sections, the uncertainty estimates for $\mathrm{Cr}$ are much larger than those for $\mathrm{Cu}$. We recommend, therefore, first a reevaluation of the covariance files for the total and elastic chromium cross-sections, and secondly, if the new uncertainty estimates are not substantially lower, a re-evaluation of the $\mathrm{Cr}$ cross-sections themselves. 
1. S. A. W. Gerstl, Donald J. Dudziak, and D. W. Muir, "Cross-Section Sensitivity and Uncertainty Analysis with Application to a Fusion Reactor," Nucl. Sci. Eng., 62, 137-156 (1977).

2. E. T. Cheng, "Generalized Variational Principles for Controlled Thermoclear Reactor Neutronics Analysis", General Atomic Company Report GA-A15378, June 1979.

3. J. M. Barnes, R. T. Santoro, and T. A. Gabriel, "The Sensitivity of the First-Wall Radiation Damage to Fusion Reactor Blanket Composition", ORNL/ TM-6105, December 1977.

4. S. A. W. Gerstl, "Sensitivity Profiles for Secondary Energy and Angular Distributions", Proc. Fifth Int. Conf. Reactor Shielding, held April 18-23, 1977, in Knoxville, Tennessee, Proceedings edited by R. W. Roussin et.al., Science Press, Princeton, 1978.

5. S. A. W. Gerst1, "Uncertainty Analysis for Secondary Energy Distributions", Proc. Seminar-Workshop on Theory and Application of Sensitivity and Uncertainty Analysis, held Aug. 22-24, 1978, in Oak Ridge, Tennessee, Proceedings edited by C. R. Weisbin et.al., ORNL/RSIC-42, Feb. 1979; see also D. W. Muir in "Applied Nuclear Data Research and Development, April 1-June 30, 1977," Los Alamos Scientific Laboratory report LA-6971-PR p. 30 (1977).

6. GA TNS Project Status Report for FY-78, Volumes I-VIII, GA-A15100, October 1978 .

7. "Fusion Energy Flow", GA-A15100, Volume IV, October 1978.

8. ENDF/B-IV, Report BNL-17541 (ENDF-201), edited by D. Garber, available from the National Nuclear Data Center (NNDC), Brookhaven National Laboratory (BNL), Upton, N.Y. (October 1975).

9. "Summary Documentation of LASL Nuclear Data Evaluations for ENDF/B-V," compiled by P. G. Young, LASL informal report LA-7663-MS, January 1979.

10. R. E. MacFarlane, R. J. Barrett, D. W. Muir, and R. M. Boicourt, "The NJOY Nuclear Data Processing System: User's Manual", Los Alamos Scientific Laboratory report LA-7584-MS (ENDF-272), December 1978.

11. "MATXS, 30x12 Neutron, Photon, and Heating Library", private communication from R. E. MacFarlane and D. W. Muir, Los Alamos Scientific Laboratory, $\mathrm{T}-2$, Feburary 18, 1973.

12. T. R. Hill, "ONETRAN: A Discrete Ordinates Finite Element Code for the Solution of the One-Dimensional Multigroup Transport Equation", Los Alamos Scientific Laboratory report LA-5990-MS, June 1975.

13. S. A. W. Gerstl, "SENSIT: A Cross-Section and Design Sensitivity and Uncertainty Analysis Code," Los Alamos Scientific Laboratory Report in preparation. 
14. F. G. Perey, "The Data Covariance Files for ENDF/B-V," ORNL/TM-5938 (1977).

15. R. E. MacFarlane, K. J. Barrett, D. W. Muir, and R. M. Boicourt, "The NJOY Nuclear Data Processing System: User's Manual," LA-7584-M (1978).

16. L. Stewart, R. J. LaBauve, P. G. Young, and D. G. Foster, Jr., ENDF/B-V Evaluation MAT 1301, personal communication through the National Nuclear Data ${ }_{1}$ Center (1979); D. G. Foster and P. G. Young, "Cross Section Covariances for ${ }^{\mathrm{H}}$," in "Summary Documentation of LASL Nuclear Data Evaluations for ENDF/B-V," LA-7663-MS (1979), p. 134.

17. G. M. Hale, L. Stewart, and P. G. Young, ENDF/B-V Evaluation MÁT 1305,

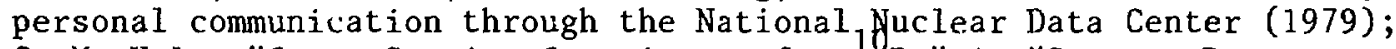
G. M. Hale, "Cross Section Covariances for 10 ," in "Summary Documentation of LASL Nuclear Data Evaluations for EMDF/B-V," LA-7663-MS (1979), p. 138.

18. C. Y. Fu and F. G. Perey, ENDF/B-V Evaluation MAT 1306, personal communication through the National Nuclear Data Center (1979).

19. A Prince and T. W. Burrows, ENDF/B-V Evaluation MAT 1324, personal communication through the National Nuclear Data Center (1979).

20. C. Y. Fu and F. G. Perey, ENDF/B-V Evaluation MAT 1326, personal communication through the National Nuclear Data Center (1979).

21. M. Divadeenam, ENDF/B-V Evaluation MAT 1328, personal communication through the National Nuclear Data Center (1979).

22. C. Y. Fu and F. G. Perey, ENDF/B-V Evaluation MAT 1382, personal communication through the National Nuclear Data Center (1979).

23. D. Hermsdorf, A. Meister, S. Sassonoff, D. Seeliger, K. Seidel, and F. Shalin, "Differentielle Neutro:lenemissionsquerschnitte $\mathrm{J}_{\mathrm{nM}}\left(\mathrm{E}_{0} ; \mathrm{E} ; \theta\right)$ bei $14.6 \mathrm{MeV}$ Einschussenergie für die Elemente $\mathrm{Be}, \mathrm{C}, \mathrm{Na}, \mathrm{Mg}, \mathrm{Al}, \mathrm{Si}, \mathrm{P}, \mathrm{S}$, $\mathrm{Ca}, \mathrm{Ti}, \mathrm{V}, \mathrm{Cr}, \mathrm{Mn}, \mathrm{Fe}, \mathrm{Co}, \mathrm{Ni}, \mathrm{Cu}, \mathrm{Zn}, \mathrm{Ga}, \mathrm{Se}, \mathrm{Br}, \mathrm{Zr}, \mathrm{Nb}, \mathrm{Cd}, \mathrm{In}, \mathrm{Sn}$, $\mathrm{Sb}, \mathrm{I}, \mathrm{Ta}, \mathrm{W}, \mathrm{Au}, \mathrm{Hg}, \mathrm{Pb}$ and $\mathrm{Bi}, "$ Zentralinstitut für Kernforschung report $2 \mathrm{KF}-277(\mathrm{U})(1975)$.

24. G. Clayeux and J. Voignier, "Diffusion Non Elastique de Neutrons de $14 \mathrm{MeV}$ sur $\mathrm{Mg}, \mathrm{Al}, \mathrm{Si}, \mathrm{S}, \mathrm{Ca}, \mathrm{Sc}, \mathrm{Fe}, \mathrm{Ni}, \mathrm{Cu}, \mathrm{Au}, \mathrm{Pb}$ et $\mathrm{Bi}$," Commissariat a $\ell^{\prime}$ Energie Atomique report CEA-R-4279 (1972).

25. D. M. Hetrick, D. C. Larson, and C. Y. Fu, "Status of ENDF/B-V Neutron Emission Spectra Induced by 14-MeV Neutrons," ORNL/TM-6637 (1979). 


\section{APPENDIX A}

In this appendix we reproduce 24 tables from the detailed SENSIT printouts for those cases of our reaction cross-section uncertainty analysis where response uncertainties greater than $10 \%$ have been obtained. The ID-numbers at the top of the tables identify the cross-section pair for which correlated uncertainties in the form of a covariance matrix have been used in the uncertainty analysis, as listed in Table III. The sensitivity profiles for each of the two reaction crosssections of each pair are also given as $P 1(G)$ and $P 2(G)$, which are printed per lethargy interval width DELTA-U. 
TNS(PGFR) XS-SENS.ANAL. FOR R1-DPA ADJ. * TF+E COILS * 156: CR,NI.FE.CU

\section{$\operatorname{cr}(t-1, t, t)$}

PI (G) AND PZ (G) ARE PER LETHARI Y UIDTH DELTR-U AND NORTAL IZED TO THE RESPONSE IIPHI FOR THE SUM OVER ALL PERTURBED ZONES, LHERE BOTH CROSS SECTIONS WITH THIS ID ARE PRESENT IN THE MDDEL THE NUMEER DENSITIES FOR THIS XS-PAIR ARE NDEN1 = 5.82808E-B3 AND NDEN2 = 5.820B8E-83

\begin{tabular}{|c|c|c|c|c|}
\hline $\begin{array}{c}\text { ROUP } \\
1 \\
2 \\
3 \\
4 \\
5 \\
6 \\
7 \\
8 \\
8 \\
9 \\
11 \\
11 \\
12 \\
13 \\
14 \\
15 \\
16 \\
17 \\
18 \\
19 \\
29\end{array}$ & 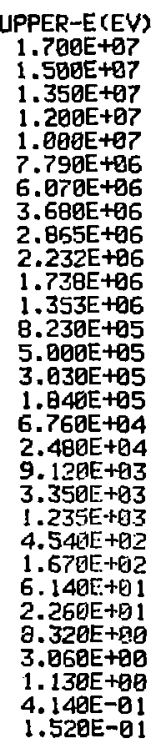 & 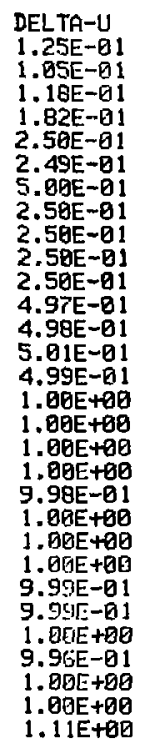 & 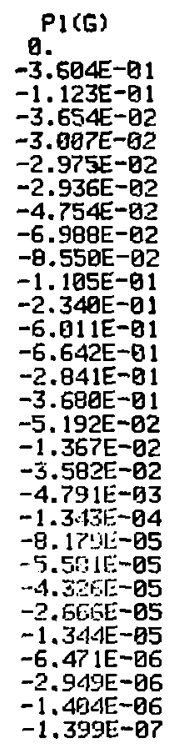 & 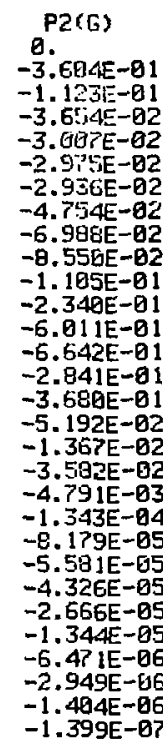 \\
\hline & & \\
\hline
\end{tabular}

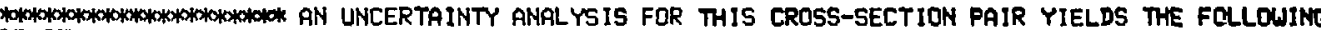
FRACTIONAL RESPONSE UNCERTAINTY DUE TO XS-UNCERTAINTIES SPECIFIED IN THE CONARIANCE WATRIX FOR THIS ID:

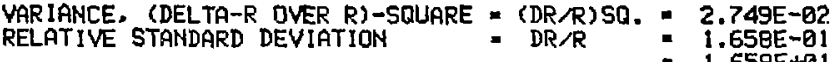
1.658E-01 PER CENT 


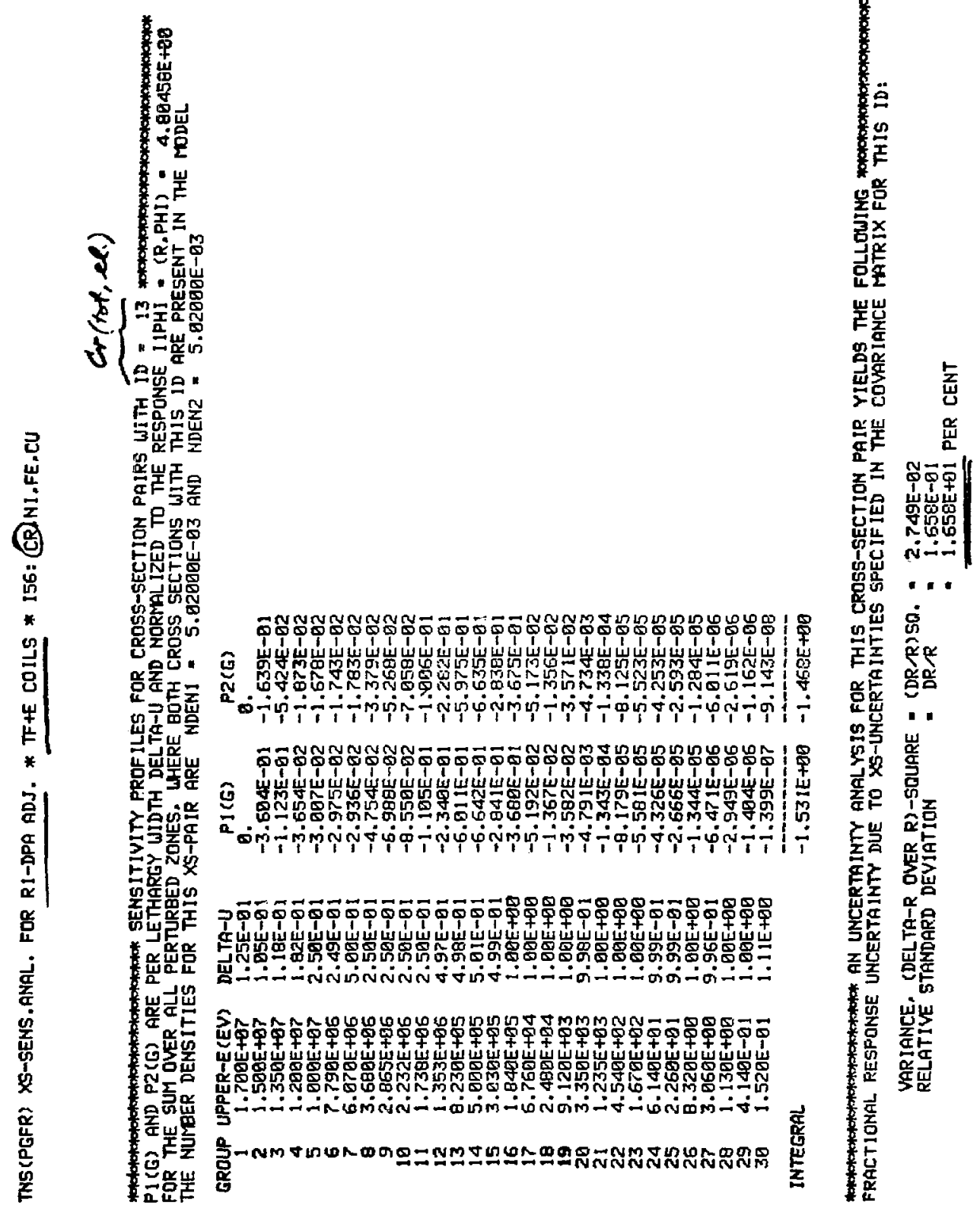


TNS(PGFR) XS-SENS.ANAL. FOR RI-DPA ADJ. * TF+E COILS* 156:CR.MI.FE,CU

\section{Cr(el, el.)}

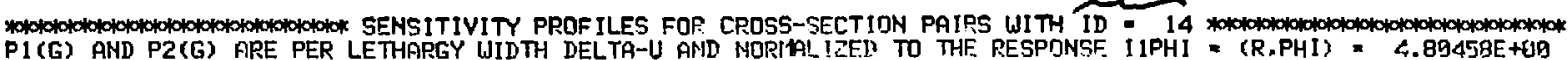

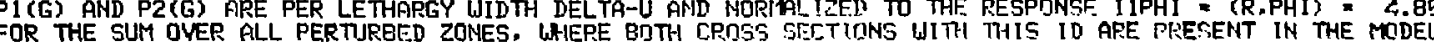

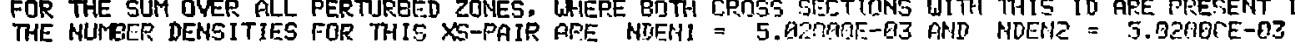

\begin{tabular}{|c|c|c|c|c|}
\hline $\begin{array}{c}20 u P \\
1 \\
2 \\
3 \\
4 \\
5 \\
6 \\
7 \\
9 \\
9 \\
16 \\
11 \\
12 \\
13 \\
14 \\
15 \\
16 \\
17 \\
18 \\
19 \\
20 \\
21 \\
22 \\
23 \\
24 \\
25 \\
26 \\
27 \\
28 \\
29 \\
30\end{array}$ & 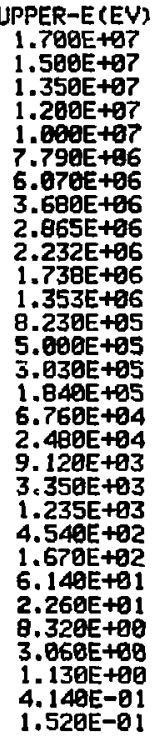 & 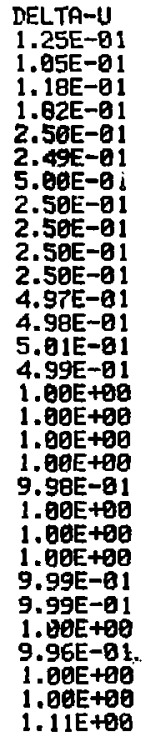 & 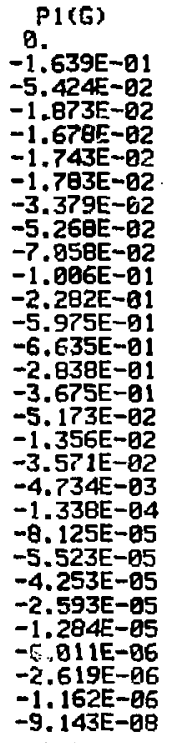 & 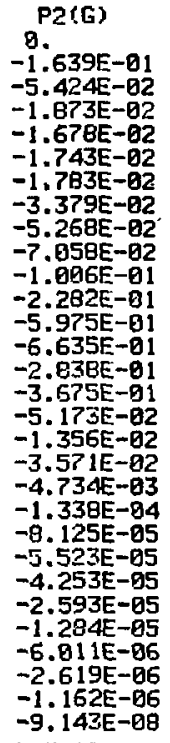 \\
\hline \multicolumn{3}{|c|}{ INTEGRA } & & \\
\hline
\end{tabular}

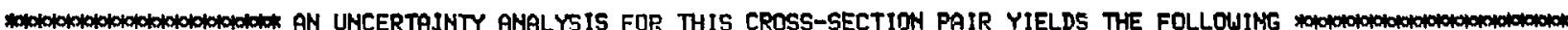

FRACTIONAL RESPONSE UNCERTAINTY DUE TO XS-UNCERTAINTIES SPECIFIED IN THE COVAR IANCE FOLLOWING
FR FOR THIS ID:

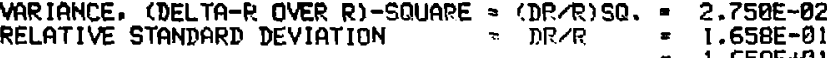

$$
\begin{aligned}
& =1.558 \mathrm{E}+1 \text { PER CENT }
\end{aligned}
$$




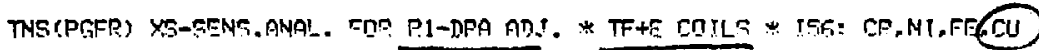

\section{Cu(tot, tot)}

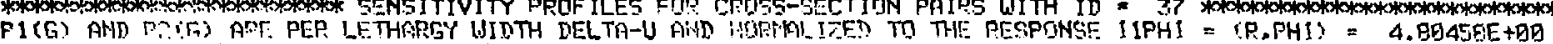

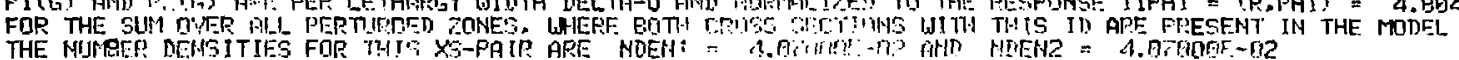

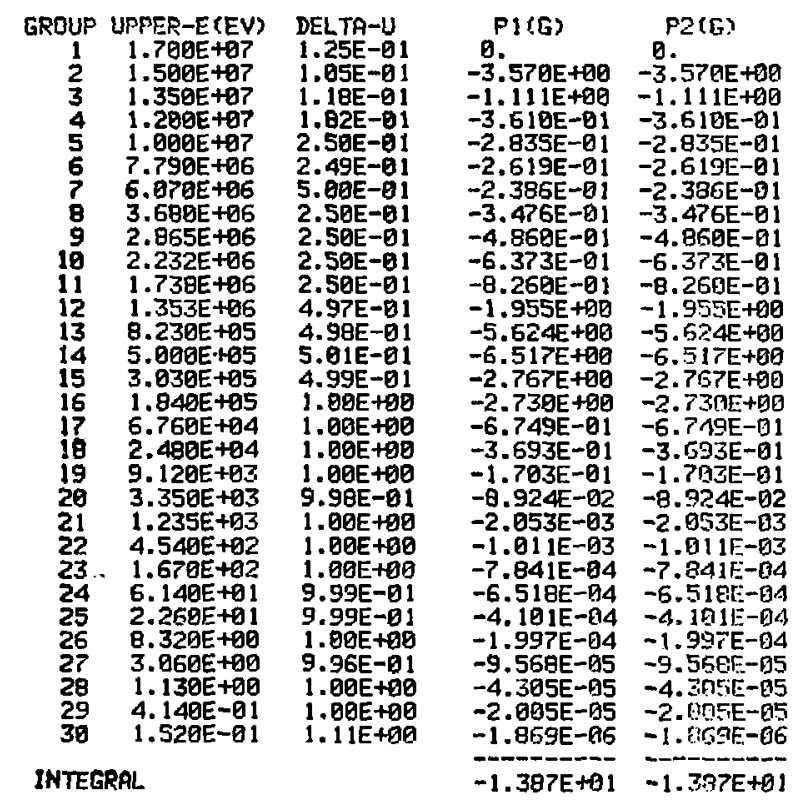

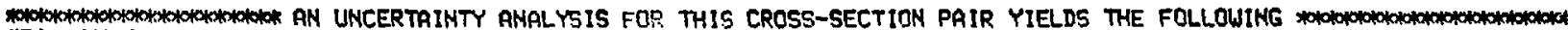
FRACTIONAL RESPONSE UNCERTAINTY DUE TO XS-UNCERTAINTIES SPECIFIED IN THE COUARIANCE MATR IX FOR THIS ID:

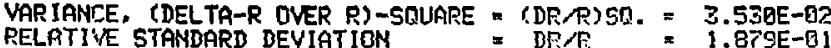

$=1.379 E+01$ PER CENT 


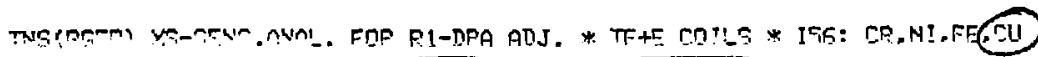

\section{$\operatorname{an}(t+1,-l)$}

TIR

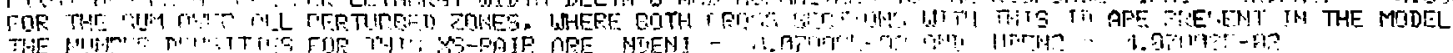

\begin{tabular}{|c|c|c|c|c|}
\hline $\begin{array}{r}r_{R} R \text { PII } \\
1 \\
2 \\
3 \\
4 \\
5 \\
5 \\
7 \\
7 \\
8 \\
9 \\
10 \\
11 \\
12 \\
13 \\
14 \\
15 \\
16 \\
17 \\
18 \\
19 \\
20 \\
21 \\
22 \\
23 \\
24 \\
25 \\
26 \\
27 \\
28 \\
29 \\
30\end{array}$ & 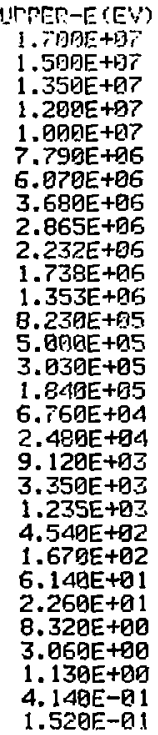 & 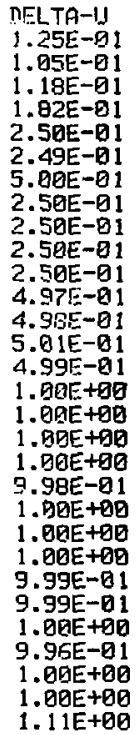 & 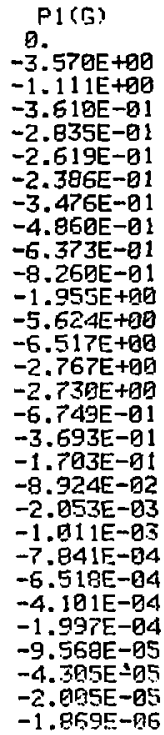 & 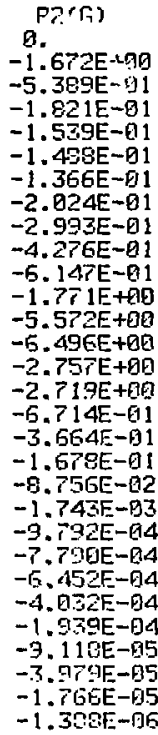 \\
\hline \multicolumn{3}{|c|}{ INTEGRAL } & $-1.387 E+n 1$ & $-1.3 t 1 E+01$ \\
\hline
\end{tabular}

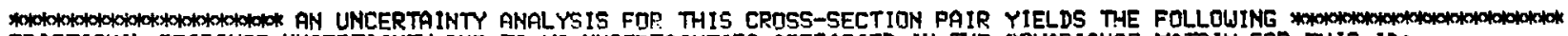
FRACTIONAL RESPONSE UNCERTAINTY DUE TO XS-UNCERTAINTIES SPECIF IED IN THE CDVARIANCE MATRIX FDR THIS ID:

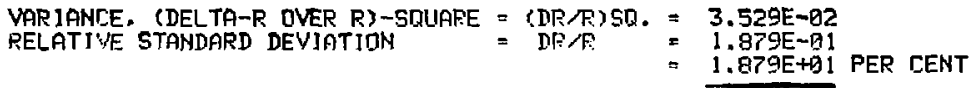


TNS (PGFP) XS-SENS.ANAL. FOR R1-DPA RDS. * TF+E COILS * I5S: CR.MI.FECCU

\section{Cu(el, $\ell_{\text {. })}$}

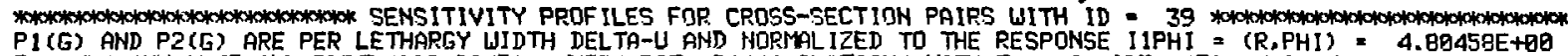

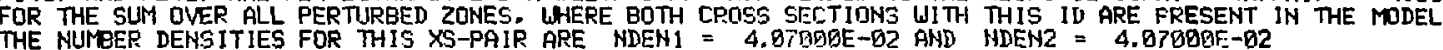

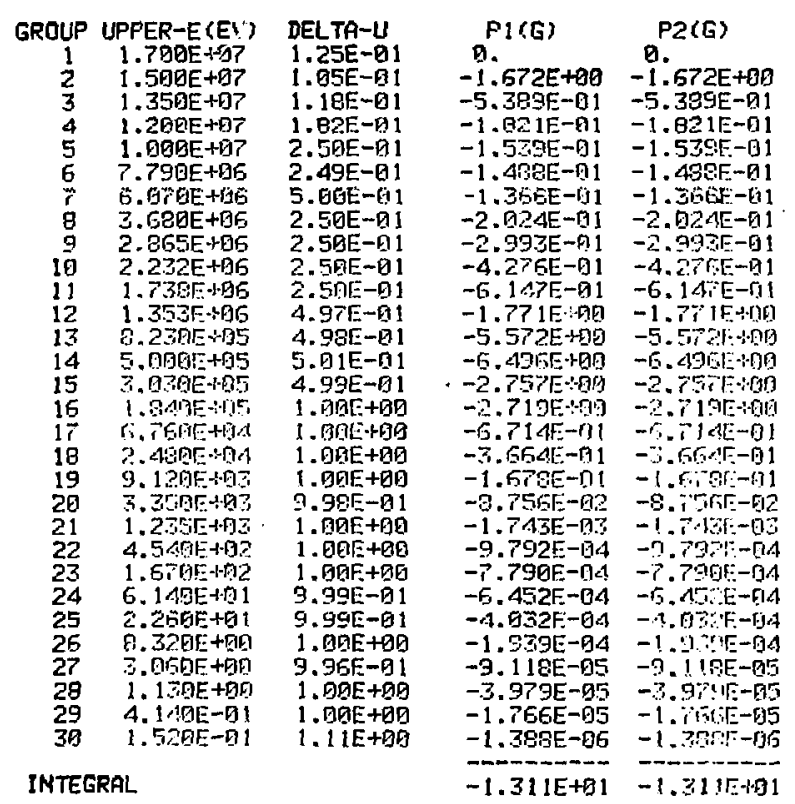

W** FRACTIOMAL RESFOHSE IJHCERTAINTY DUE TO YS-UNCIEPTA IHTTES SPECIFIED IN THE COVAPIANCE MUTRIX FOR THIS ID:

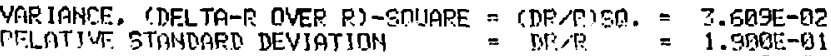

$$
\begin{aligned}
& =1.90 \mathrm{gE}+1 \mathrm{PER} \text { CENT }
\end{aligned}
$$




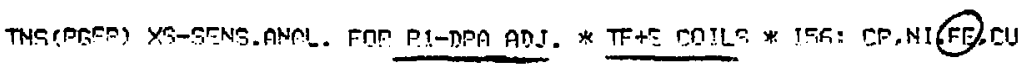

\section{$\operatorname{Fe}($ tot, tot $)$}

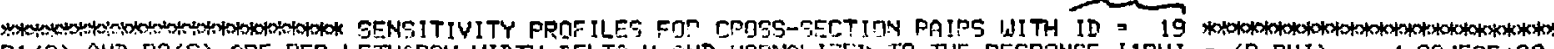

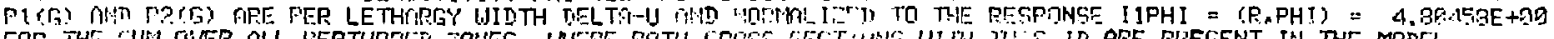

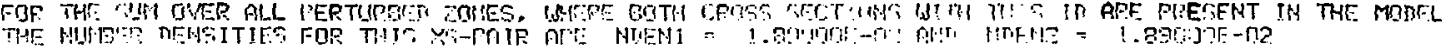

\begin{tabular}{|c|c|c|c|c|}
\hline $\begin{array}{c}R 0 y C \\
1 \\
2 \\
3 \\
4 \\
5 \\
6 \\
7 \\
8 \\
9 \\
10 \\
11 \\
12 \\
13 \\
14 \\
15 \\
16 \\
17 \\
18 \\
19 \\
29 \\
21 \\
22 \\
23 \\
24 \\
25 \\
26 \\
27 \\
28 \\
29 \\
30\end{array}$ & 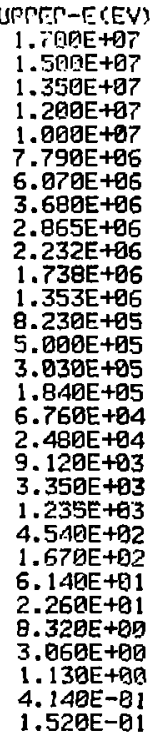 & 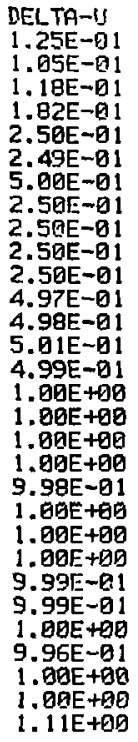 & 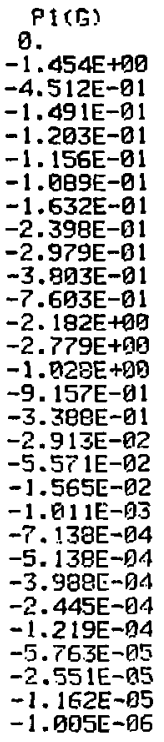 & 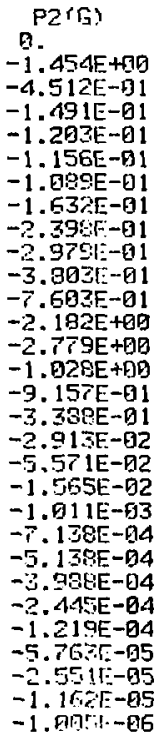 \\
\hline \multicolumn{3}{|c|}{ INTEGRA } & & 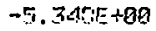 \\
\hline
\end{tabular}

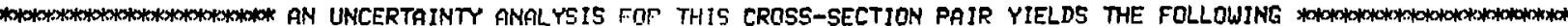
FRACTIOHAL PESPOHSE UIHCERTAIHTY DIUE TO KS-UMCFTIAYHTIES SPECIFIED IN THE COVAR IANCE MATR IX FOR THIS ID:

$$
\begin{aligned}
& \text { VAR IANICF. (NELTA-R GVER R)-SOIJARE = PNT/PISO. = } 6.317 E-03
\end{aligned}
$$

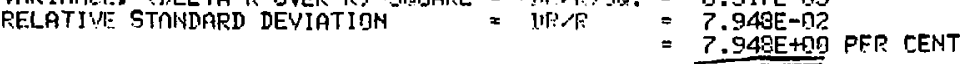




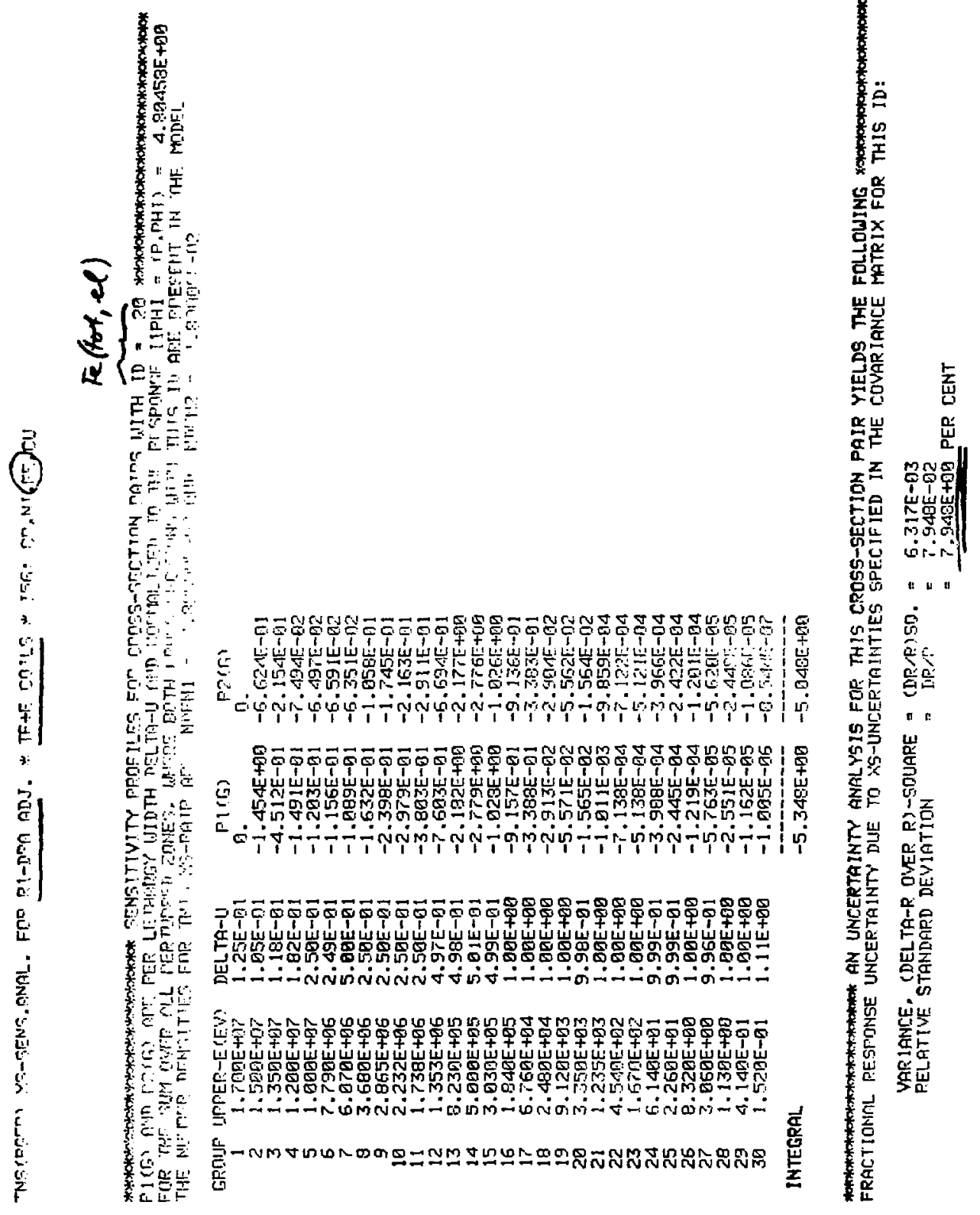


TNS IPGER, XS-SFNG.AMAL. FOR R1-DPA ADJ. * TF+E COILS * 156: CP.MI(FF)CIJ

\section{Fe(ed, el. $)$}

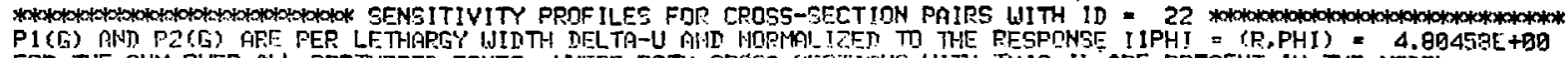

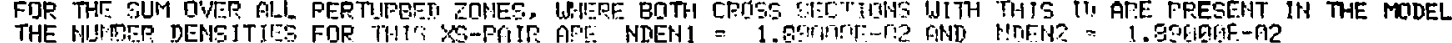

\begin{tabular}{|c|c|c|c|c|}
\hline $\begin{array}{c}\text { GROUP } \\
1 \\
2 \\
3 \\
4 \\
5 \\
6 \\
7 \\
9 \\
9 \\
19 \\
11 \\
12 \\
13 \\
14 \\
15 \\
16 \\
17 \\
18 \\
19 \\
29 \\
21 \\
22 \\
23 \\
24 \\
25 \\
26 \\
27 \\
28 \\
29 \\
30\end{array}$ & 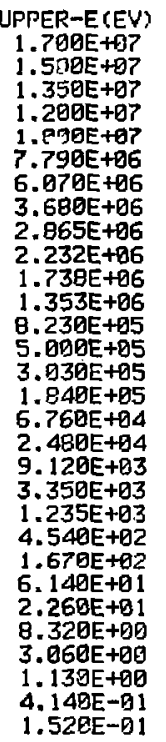 & 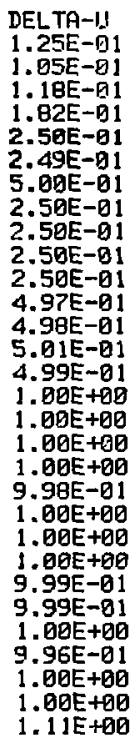 & 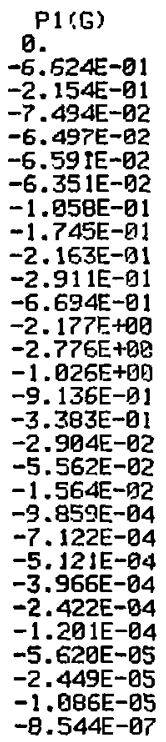 & $\begin{array}{l}P 2(G) \\
0 . \\
-6.624 E-01 \\
-2.154 \mathrm{E}-01 \\
-7.494 \mathrm{E}-02 \\
-6.497 \mathrm{E}-92 \\
-6.591 \mathrm{E}-02 \\
-6.351 \mathrm{E}-02 \\
-1.958 \mathrm{E}-01 \\
-1.745 \mathrm{E}-01 \\
-2.163 \mathrm{E}-01 \\
-2.511 \mathrm{E}-91 \\
-6.694 \mathrm{E}-01 \\
-2.177 \mathrm{E}+90 \\
-2.776 \mathrm{E}+90 \\
-1.926 \mathrm{E}+00 \\
-9.136 \mathrm{E}-01 \\
-3.383 \mathrm{E}-01 \\
-2.994 \mathrm{E}-02 \\
-5.562 \mathrm{E}-02 \\
-1.564 \mathrm{E}-02 \\
-9.259 \mathrm{E}-04\end{array}$ \\
\hline \multicolumn{3}{|c|}{ INTEGRAL } & & \\
\hline
\end{tabular}

FRACTIONAL RESPONSE UNCERTAINTY DUE TO XS-UNCERTAINTIES SPECIFIED IN THE COVARIANLE MATRIX FOR THIS ID:

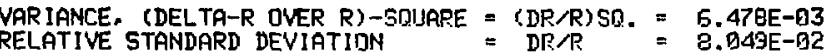

$$
\begin{aligned}
& =\text { B. Q49E+QB PER CENT }
\end{aligned}
$$


SENSIT SAMPLE E, *FUSION REACTOR*VECTOR-XS. SEN+UNCERT.*RUN76:CR, NI, FE, CU

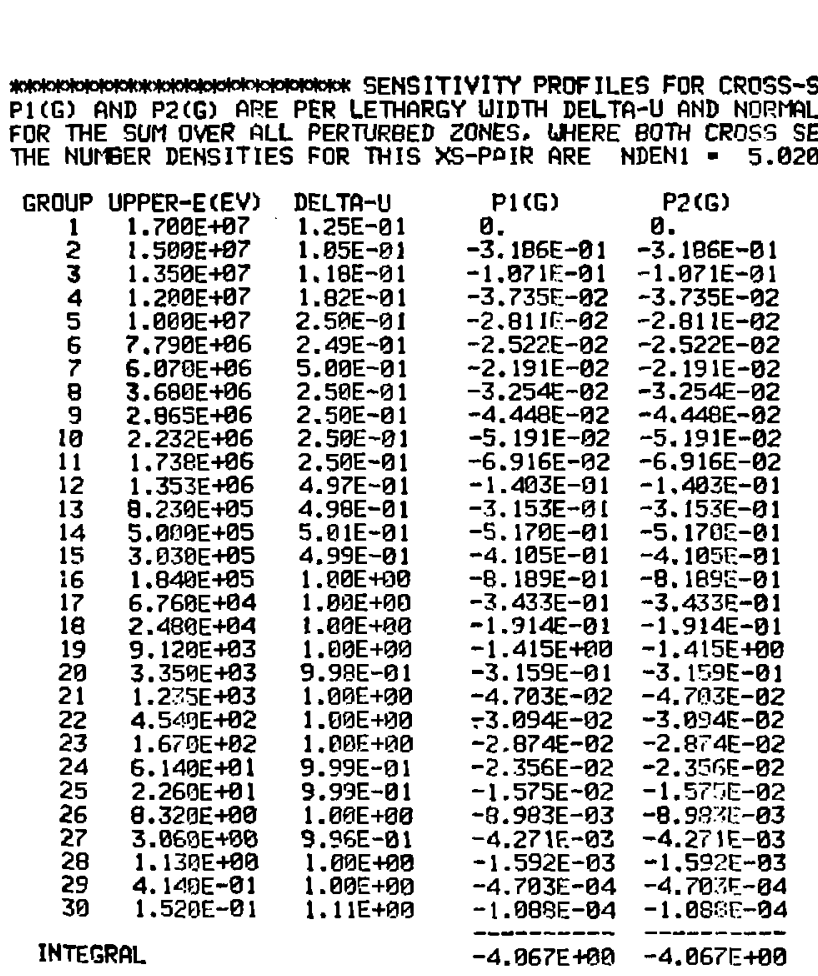

FPA FRACTIONAL RESPONSE UNCERTAINTY DUE TO XS-UHICERTAINTIES SPECIFIED IN THE COVARIANCE MATR IX FOR THIS ID:

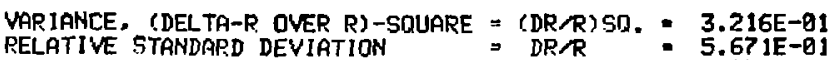

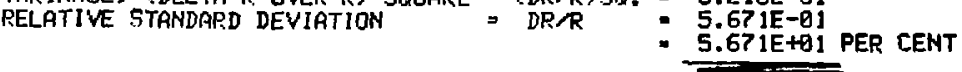

\section{Cr (tof, tot)}

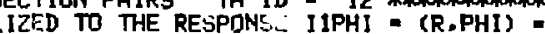
SECTIDNS WITH THIS ID ARE PRESENT IN THE MODEL
$5.02000 \mathrm{E}-03$ 
SENSIT SAMPLE B. *FUSIDN REACTOP:WVECTDR-XS.SEN+UNCERT.*RUN75, CR. N1. FE. CU

\section{Cor(.6f, el. $)$}

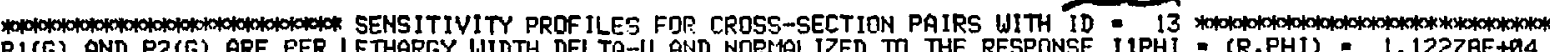

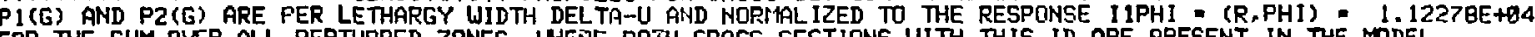
FOR THE SUM OYER ALL PERTURBED ZONES, WHERE BOTH CROSS SECTIONS WITH THIS ID ARE PRESENT IN THE MDDEL

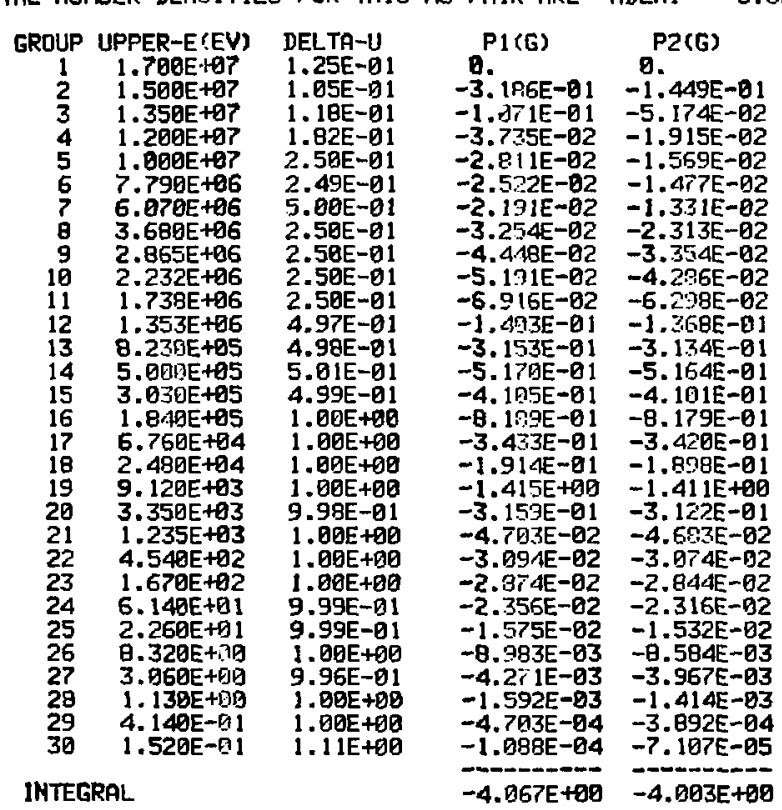

* FRACTIDHAL RESFIHSE INICERTAINTY DUE TO XS-UNCERTAINTIES SPECIFIED IN THE COUARIANCE MATRIX FOR THIS ID:

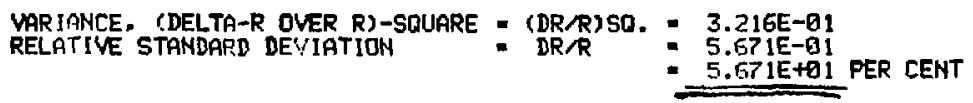




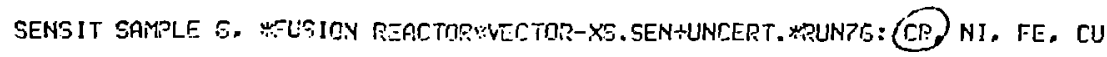

\section{$\operatorname{cr}(e l, e l$.}

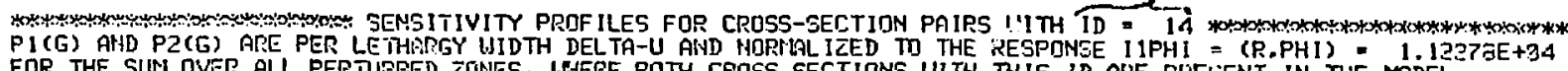

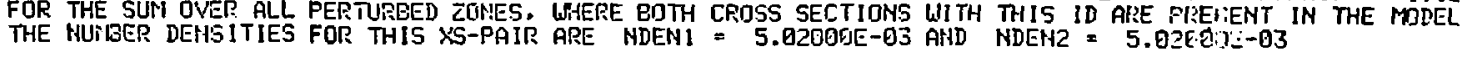

\begin{tabular}{|c|c|c|c|c|}
\hline $\begin{array}{c}\text { GROUP } \\
1 \\
2 \\
3 \\
4 \\
5 \\
6 \\
7 \\
7 \\
8 \\
9 \\
19 \\
11 \\
12 \\
13 \\
14 \\
15 \\
16 \\
17 \\
18 \\
19 \\
20 \\
21 \\
22 \\
23 \\
24 \\
25 \\
26 \\
27 \\
23 \\
29 \\
30\end{array}$ & 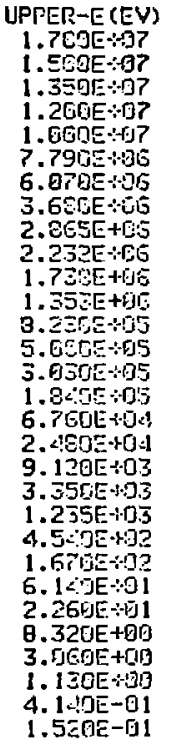 & 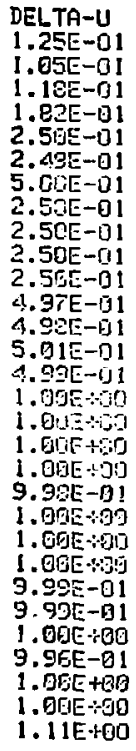 & 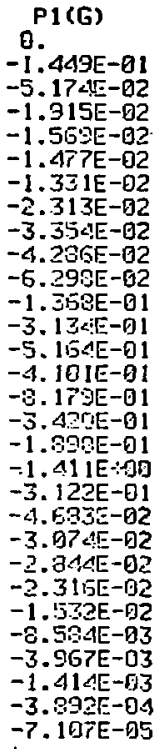 & 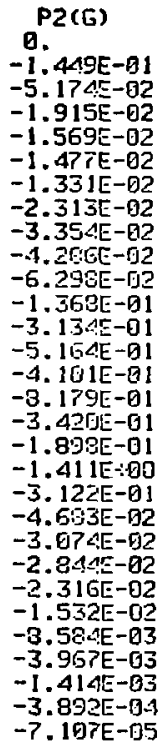 \\
\hline \multicolumn{3}{|c|}{ INTEGRAL } & -4 & \\
\hline
\end{tabular}

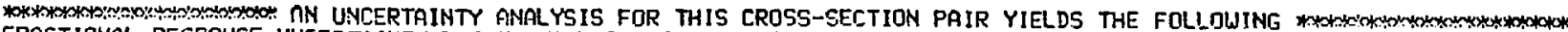
FRACTIOHAL RESFOHSE UHCERTAINTY DUE TO XS-UNCERTAINTIES SPECIFIED IN THE COVARIAHCE MKTRIX FOR THIS ID:

VARIANCE. (DELTA-R. DUER R)-SMUARE = (DRAR)SR. = 3.216E-D1

$\begin{aligned} \text { RELATIVE GIHAILARD DEVIATIDN }=\text { DRJR } & : 5.671 E-01 \\ & =5.671 E+01 \text { PER CENT }\end{aligned}$ 
BENSIT SATPLE 0. XUS!CY REACTORXVECTOR-YS.SEN+UNCERT.*RUMT6: CR. (NI) FE, CU

\section{Ni tort, tot)}

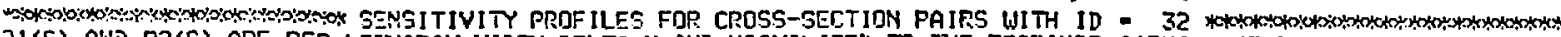

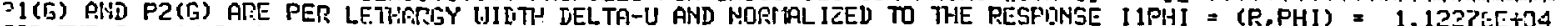
=OR THE SUH OVER ALL PERTUREET ZONES, WHERE EOTI CROSS SECTIONS IJI TH THIS ID ARE FRESENT IN THE MOLEL

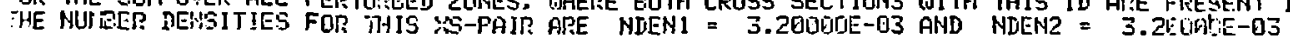

\begin{tabular}{|c|c|c|c|c|}
\hline $\begin{array}{c}\text { GROUP } \\
1 \\
2 \\
3 \\
4 \\
5 \\
6 \\
7 \\
8 \\
9 \\
10 \\
11 \\
12 \\
13 \\
14 \\
15 \\
16 \\
17 \\
18 \\
19 \\
29 \\
21 \\
22 \\
23 \\
24 \\
25 \\
26 \\
27 \\
28 \\
29 \\
30\end{array}$ & 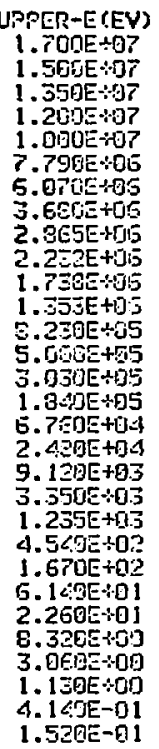 & 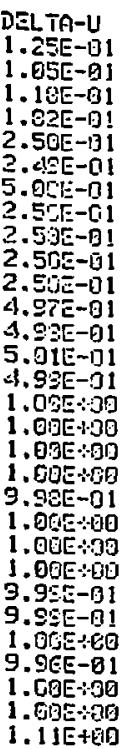 & 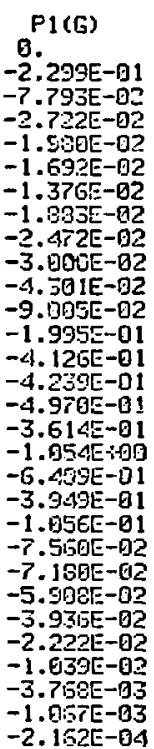 & 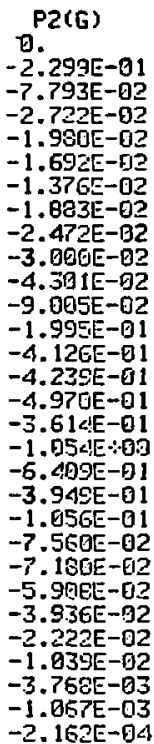 \\
\hline \multicolumn{3}{|c|}{ INTEGPAL } & $E \div 90$ & \\
\hline
\end{tabular}

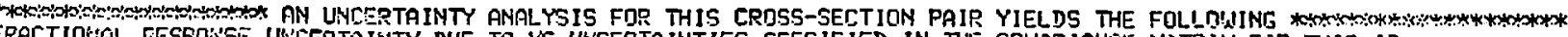
RACTIOHAL FESFONSE UN'CERTAINTY DUE TO :SS-UHCERTAINTIES SFECIFIED IN THE COVARIANEE MITRIX FUR THIS ID:

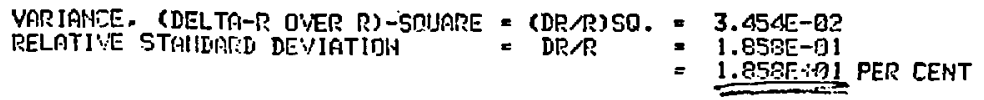




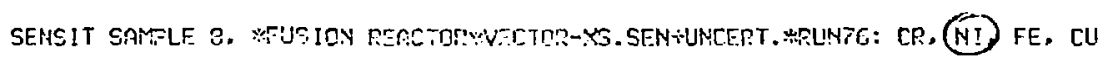

\section{Ni(el,el)}

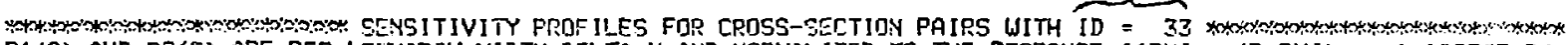

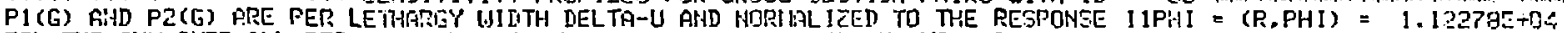

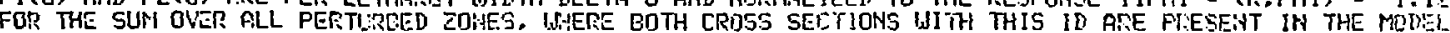

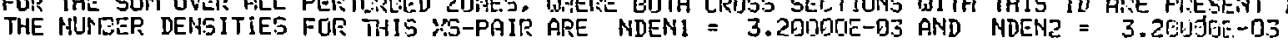

\begin{tabular}{|c|c|c|c|c|}
\hline $\begin{aligned} 6 R O L P \\
1 \\
2 \\
3 \\
4 \\
4 \\
5 \\
6 \\
7 \\
8 \\
9 \\
19 \\
11 \\
12 \\
13 \\
14 \\
15 \\
16 \\
17 \\
18 \\
19 \\
29 \\
21 \\
22 \\
23 \\
24 \\
25 \\
26 \\
27 \\
28 \\
29 \\
30\end{aligned}$ & 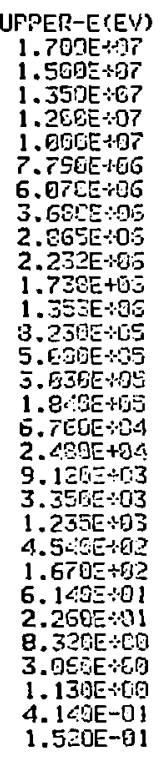 & 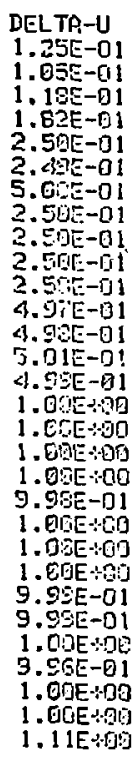 & 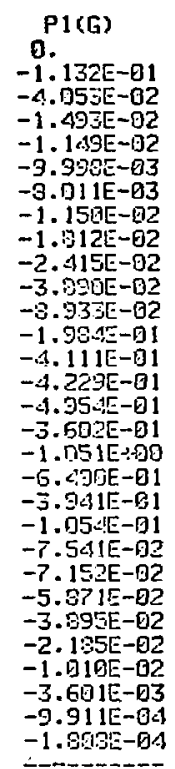 & 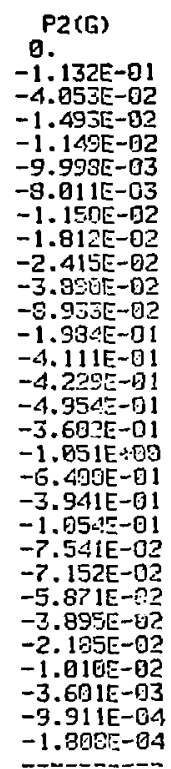 \\
\hline \multicolumn{3}{|c|}{ INTEGPA } & & \\
\hline
\end{tabular}

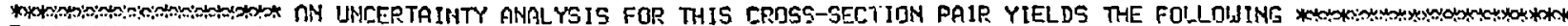
FRACTIOHAL FESPCIISE UIICERTAIHTY DIJE TO $\%$ G-UHCERTAINTIES SPECIFIED IN THE COVAR IAMCE MGTRIK FOR THIS ID:

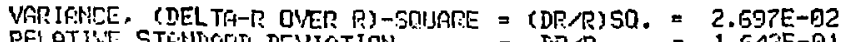

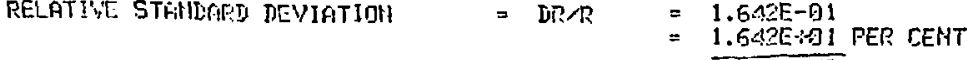


SENSIT SAMPLE 8, *FUSION REACTOR*VECTOR-XS.SEN+UNCERT,*RUN75: CR, NI. FE. CU

\section{$\operatorname{Fe}(t, t, t, t)$}

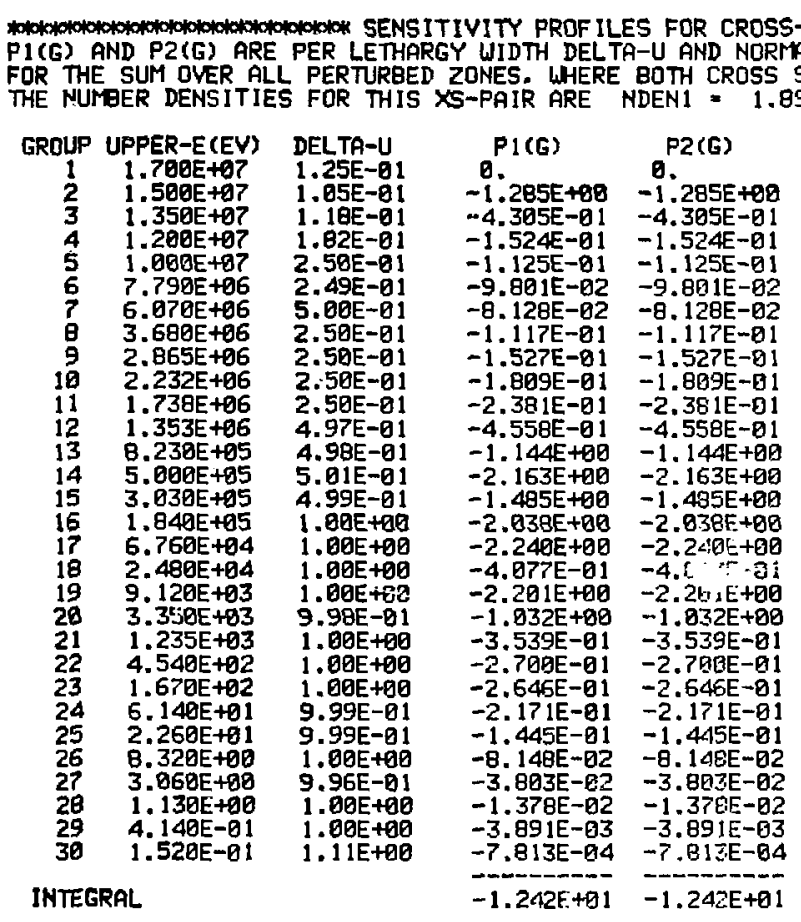

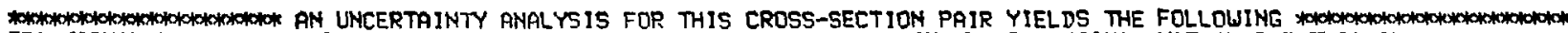
FRACTIONAL RESPONSE UNCERTAINTY DUE TO XS-UNCERTAINTIES SPECIFIED IN THE COVAR IANCE MATR IX FOR THIS IN:

$$
\begin{aligned}
& \text { YARIANCE. (DELTA-R OVER R)-SOUARE = (DR/R)SO. }=8.177 E-93 \\
& \begin{aligned}
\text { RELATIVE STANDARD DEVIATION }=\text { DR } \mathrm{R} & =9.943 E-02 \\
& =9.043 \mathrm{E}+90 \text { PER CENT }
\end{aligned}
\end{aligned}
$$


SENSIT SAMPLE 8. *FUSION REACTMP*VECTDR-YS.SEM+UNCERT. *RUNPG: CR, N1.FE. CU

\section{$F(t+1, e l)$}

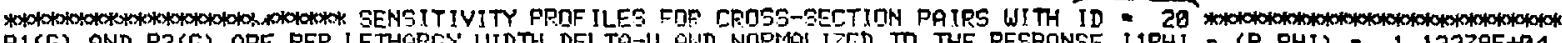

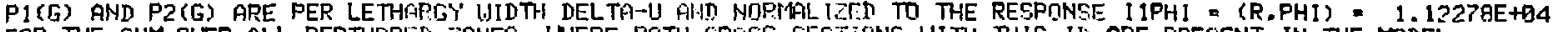
FOR THE SUM OVER ALL PERTIPEEED ZOHES. WHERE BOTH CRISS SFCTIONS WITH THIS ID ARE PRESENT IN THE MODEL

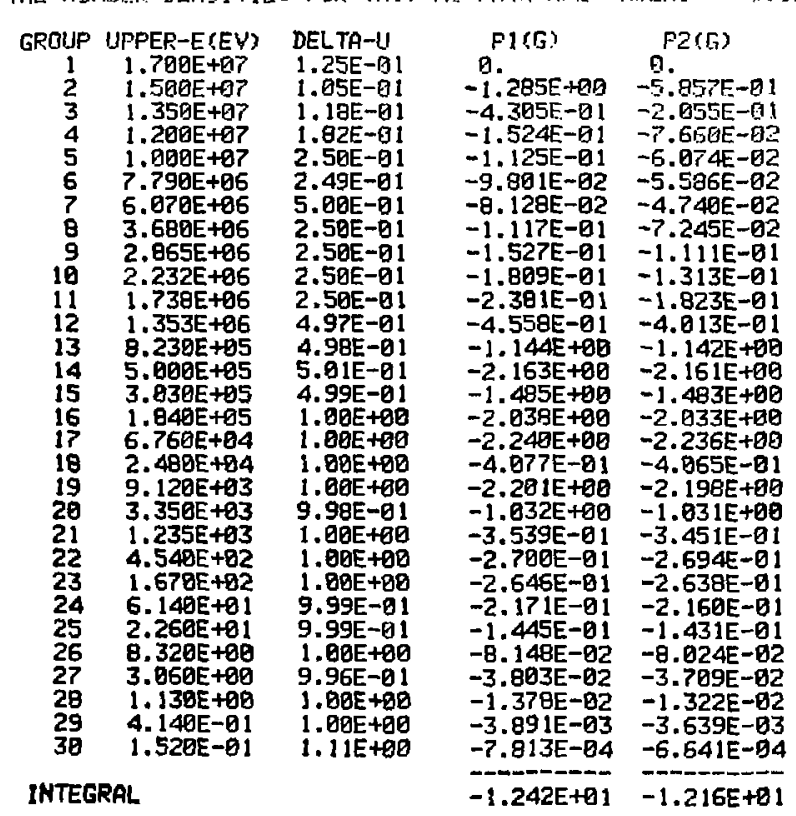

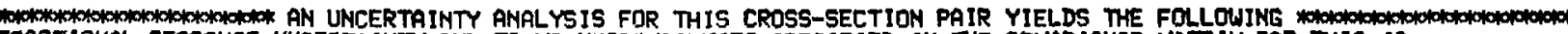
FRACTIONAL RESPONSE UNCERTAINTY DUE TO XS-UNCERTAINTIES SPECIFIED IN THE CONAR IANCE MATRIX FOR THIS ID:

VAR IANCE, (DELTA-R OYER R)-SOUARE = (DR R ISO. = 8.175E-Q3

RELATIVE STANDARD DEVIATION 
SENSIT SAMPLE 8. WFUSION REACTOR*VECTRR-XS. SEN+UNCERT.*RUN7G: CR, NI, FE, CU

$$
\operatorname{re}(e l, e l)
$$

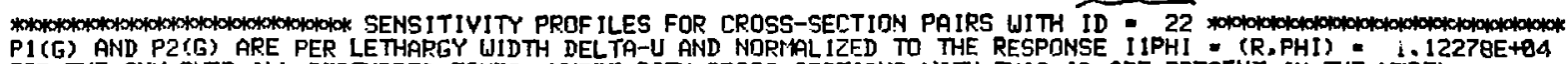
P1(G) AND P2 (G) ARE PER LETHARGY UIDTH DELTA-U AND NDRTAL IZED TO THE RESPDNSE IIPHI OE, PHI) FOR THE SUM DVER ALL PERTURBED ZONES* WHERE QDTH CRDSS SECTIONS WITH THIS ID ARE PRESENY

\begin{tabular}{|c|c|c|c|c|}
\hline $\begin{array}{c}\text { GRDUP } \\
1 \\
2 \\
3 \\
4 \\
5 \\
6 \\
7 \\
8 \\
9 \\
18 \\
11 \\
12 \\
13 \\
14 \\
15 \\
16 \\
17 \\
18 \\
19 \\
20 \\
21 \\
22 \\
23 \\
24 \\
25 \\
26 \\
27 \\
28 \\
29 \\
30\end{array}$ & 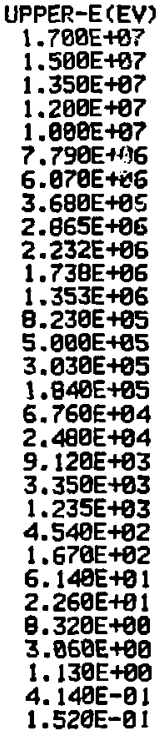 & 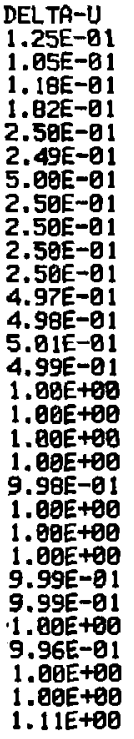 & 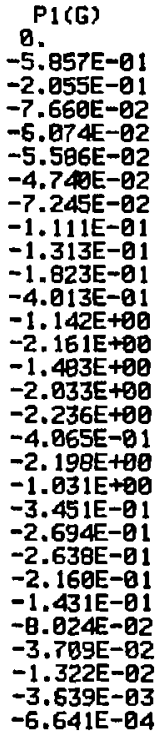 & 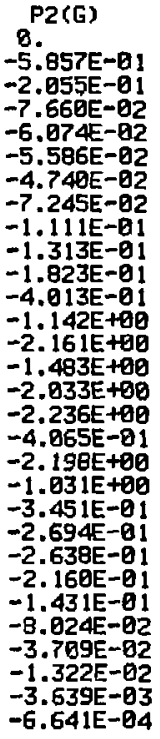 \\
\hline \multicolumn{3}{|c|}{ INTEGRAL } & & \\
\hline
\end{tabular}

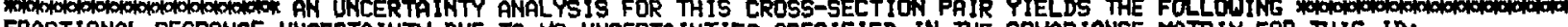
FRACTIONAL RESPONSE UNCERTAINTY DUE TO XS-UNCERTAINTIES SPECIFIED IN THE COVARIANCE MPTRIX FOR THIS ID:

$$
\begin{aligned}
& \begin{array}{l}
\text { YAR IANCE. (DELTA-R OVER R)-SOUARE = (DR/R)SR. : } 9.258 E-03 \\
\text { RELATIVE STANDARD DEVIATIOM }
\end{array} \\
& \text { RELATIVE STANDARD DEVIATION }=\text { DR/R : } 9.087 \mathrm{9} \text {-097E+00 PER CENT }
\end{aligned}
$$


SENSIT SAMPLE 8. *FUSION REACTOR*VECTOR-XS.SEN+UNCERT. *RUNTE: CR. NI. FE. (CU)

\section{$\operatorname{Cu}(t a t$, thf)}

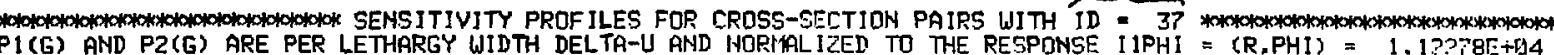

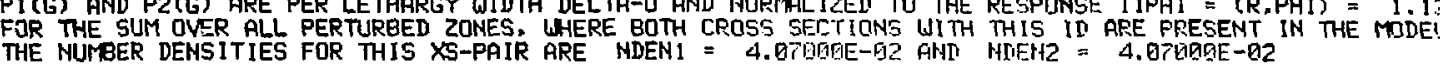

\begin{tabular}{|c|c|c|c|c|}
\hline $\begin{array}{c}\text { GROUP } \\
1 \\
2 \\
3 \\
3 \\
4 \\
5 \\
6 \\
7 \\
8 \\
8 \\
9 \\
10 \\
11 \\
12 \\
13 \\
14 \\
15 \\
16 \\
17 \\
18 \\
19 \\
29 \\
21 \\
22 \\
23 \\
24 \\
25 \\
26 \\
27 \\
28 \\
29 \\
39\end{array}$ & 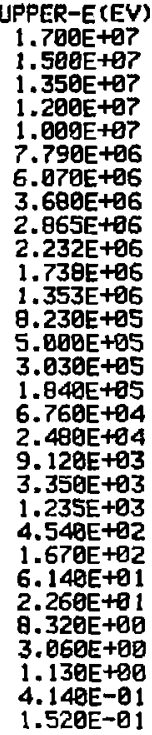 & 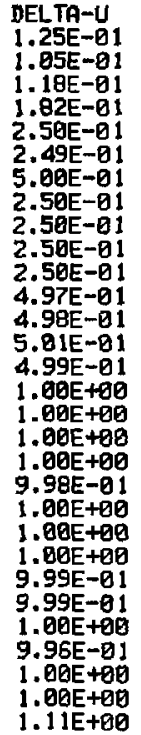 & 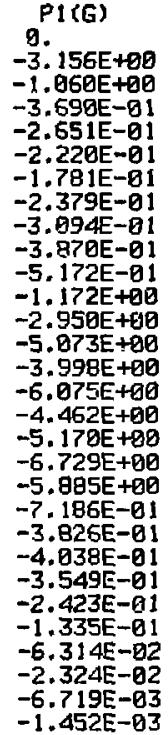 & 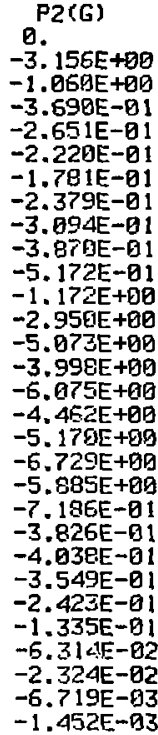 \\
\hline \multicolumn{3}{|c|}{ INTEGRF } & & $5 E+01$ \\
\hline
\end{tabular}

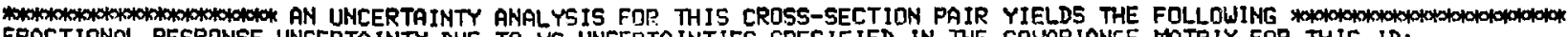
FRACTIONAL RESPONSE UNCERTAINTY DUE TO XS-UNACERTAINTIES SPECIFIED IN THE CONAR IANCE MATRIX FDR THIS ID:

VARIANCE. (DELTA-R OVER R)-SOUARE = (MR/R) SO. = 6.769E-D2

$\begin{aligned} \text { RELATIVE STANDARD DEVIATIDN }=\text { DF } / \mathrm{F}: & =2.602 \mathrm{E}-01 \\ & =2.602 \mathrm{E}+01 \text { PER TENT }\end{aligned}$ 
SENSIT SAMPLE B. *FUSION REACTOR*VECTOR-XS.SEN+UNCERT. *RUNT6: CR. NI, FE CU

\section{$\operatorname{cu}(t+1, e l)$}

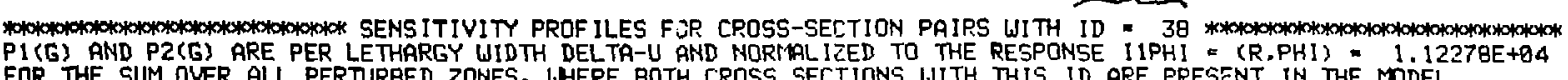

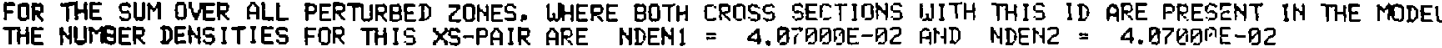

\begin{tabular}{|c|c|c|c|c|}
\hline $\begin{array}{c}\text { GROUP } \\
1 \\
2 \\
3 \\
4 \\
5 \\
6 \\
7 \\
8 \\
9 \\
19 \\
11 \\
12 \\
13 \\
14 \\
15 \\
16 \\
17 \\
18 \\
19 \\
20 \\
21 \\
22 \\
23 \\
24 \\
25 \\
26 \\
27 \\
29 \\
29 \\
30\end{array}$ & 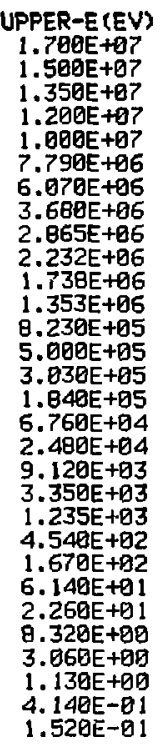 & 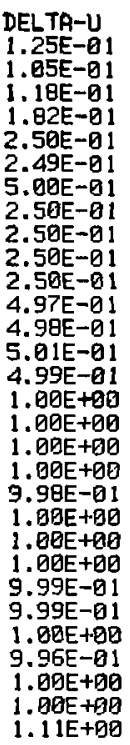 & 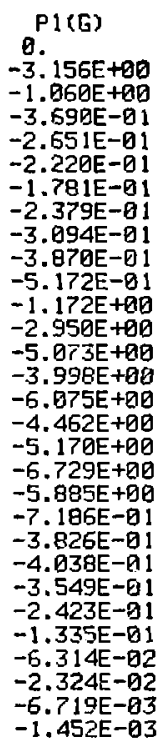 & 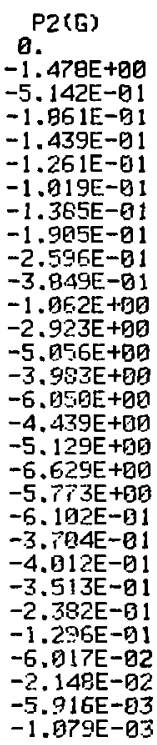 \\
\hline \multicolumn{3}{|c|}{ INTEGRAL, } & $3.836 \mathrm{E}+91$ & $5 \mathrm{E}+01$ \\
\hline
\end{tabular}

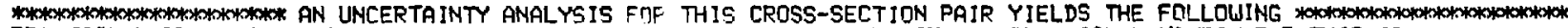

FRACTIONAL RESPOHSE UNCERTAINTY DUE TO XS-UNCEPTAINTIES SPECIFIED IN THE COVARIPACE MATRIX FDR THIS ID:

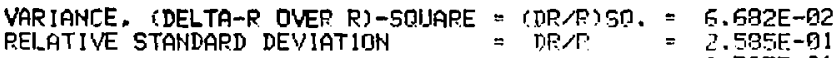

$$
\begin{aligned}
& 2 \text {. }
\end{aligned}
$$


SENSIT SAMPLE 8. *FUSION REACTOR*VECTOR-XS.SEN+UNCERT, *RIJNTE: CR. NI, FE, CU

\section{$\mathrm{Cu}(\mathrm{el}, \mathrm{el})$}

* P1(G) AND P2(G) ARE PER LETHARTY WHDTH DELTA-U AHD HCIPHALIZER TD THE RESPONSE IIPHI $=$ (R, PHI) E $1.12278 E+04$

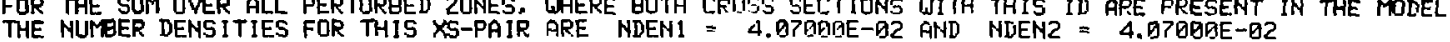

\begin{tabular}{|c|c|c|c|c|}
\hline $\begin{array}{c}\text { GROUP } \\
1 \\
2 \\
3 \\
4 \\
4 \\
5 \\
6 \\
7 \\
8 \\
9 \\
19 \\
11 \\
12 \\
13 \\
14 \\
15 \\
16 \\
17 \\
18 \\
19 \\
29 \\
21 \\
22 \\
23 \\
24 \\
25 \\
26 \\
27 \\
28 \\
29 \\
30\end{array}$ & 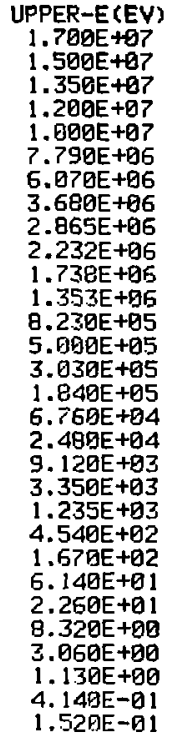 & 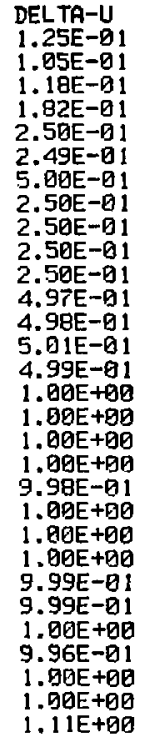 & 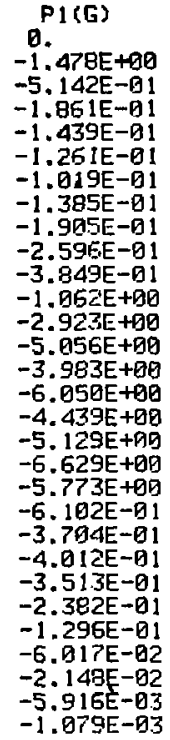 & 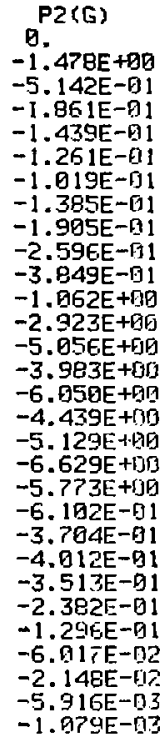 \\
\hline \multicolumn{3}{|c|}{ INTEGRAL } & 35 & -3.7 \\
\hline
\end{tabular}

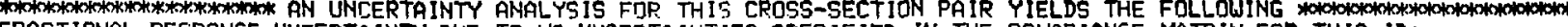
FRACTIONAL PESPPNSE UNCERTAINTY DUE TO XS-UNCEPTAINTIES SPECIFIED IN THE COVARIRHIEE MATRIX FOR THIS ID:

VAR IANCE, (DELTA-R DVER R)-SQUARE = (DRAR) SR. = E.626E-D2

$\begin{aligned} \text { PELATIVE STANDARD DEVIATION }=\text { DP } P \text {. } & =2.574 E-91 \\ & =2.57 \text { AE+Q1 PER CENT }\end{aligned}$ 
TNS(PGFR) XS-SENS. -ANAL YSIS FOR R3-TF-COIL KERMA *** SHIELD* I75: H.O@W

\section{P6 (tot, tot)}

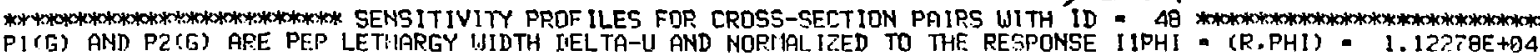

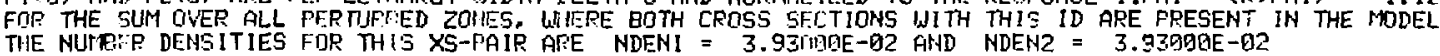

\begin{tabular}{|c|c|c|c|c|}
\hline $\begin{array}{c}\text { GPOUP } \\
1 \\
2 \\
3 \\
4 \\
5 \\
6 \\
7 \\
8 \\
9 \\
19 \\
11 \\
12 \\
13 \\
14 \\
15 \\
16 \\
17 \\
19 \\
19 \\
25 \\
21 \\
22 \\
23 \\
24 \\
25 \\
25 \\
27 \\
29 \\
39 \\
30\end{array}$ & 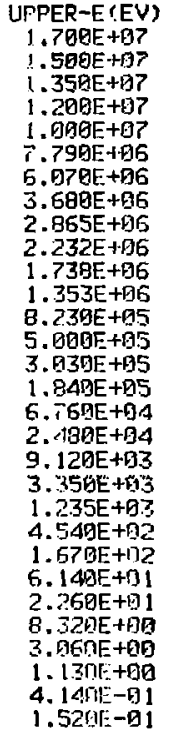 & 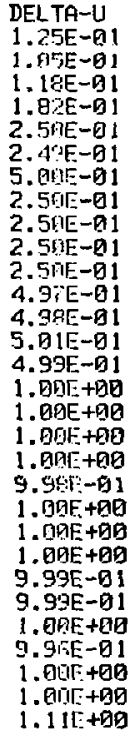 & 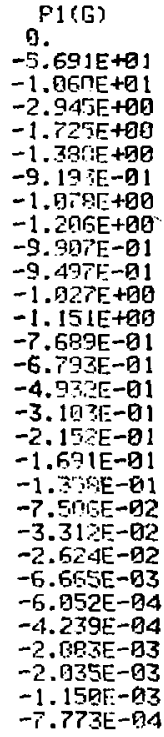 & 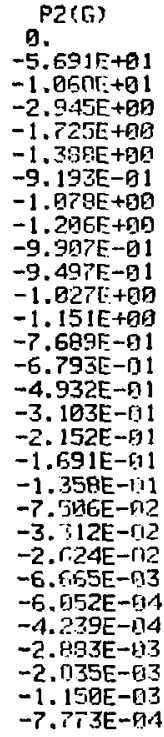 \\
\hline \multicolumn{3}{|c|}{ INTEGPAL } & $36 \mathrm{E}+01$ & $36 \mathrm{E}-1 \cdot 91$ \\
\hline
\end{tabular}

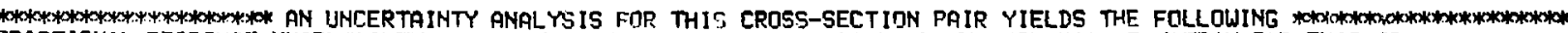

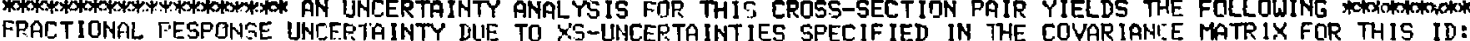

$$
\begin{aligned}
& \text { MAR IANCE, (DELTA-R DYER P)-SQUARE - (DR/R) SD. - 7.4B9E-QD2 }
\end{aligned}
$$

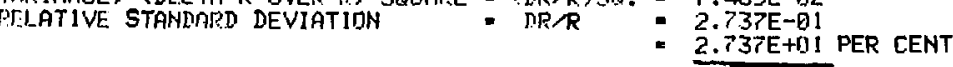




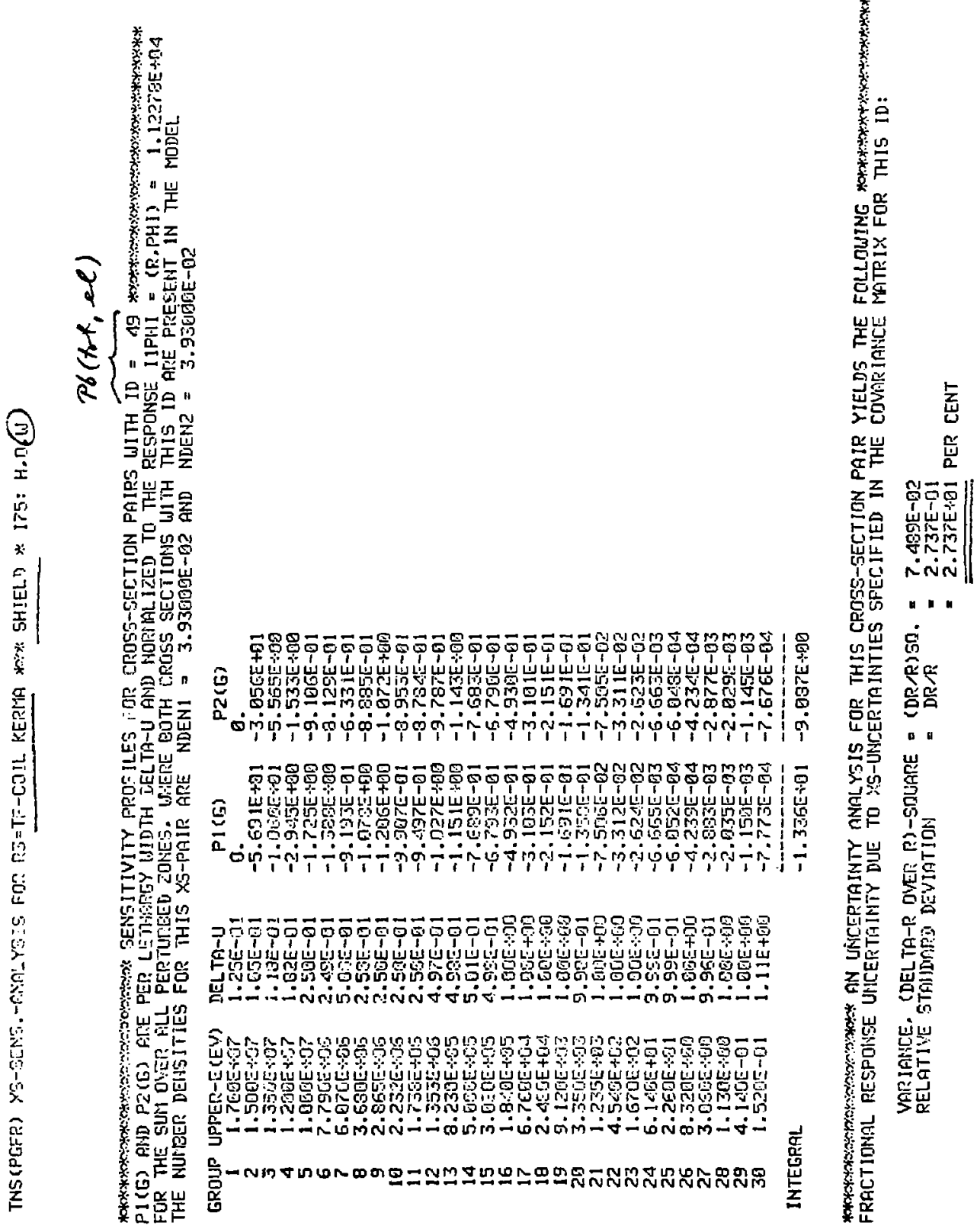




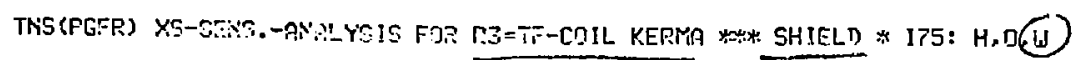

\section{P6 (el,el.)}

PI (G) AND P2 (G) FIRE PEP SENSITIVITY PROF ILES FOR CROSS-SECTION PAIRS WITH ID FOR THE SUM OU) THE NUPBER DEWSITIES FOR THIS XSTAIR AFE NDEHI =

\begin{tabular}{|c|c|c|c|c|}
\hline $\begin{array}{c}\text { GROUP } \\
1 \\
2 \\
3 \\
4 \\
5 \\
6 \\
7 \\
8 \\
9 \\
19 \\
11 \\
12 \\
13 \\
14 \\
15 \\
16 \\
17 \\
19 \\
19 \\
29 \\
21 \\
22 \\
23 \\
24 \\
25 \\
26 \\
27 \\
28 \\
29 \\
30\end{array}$ & 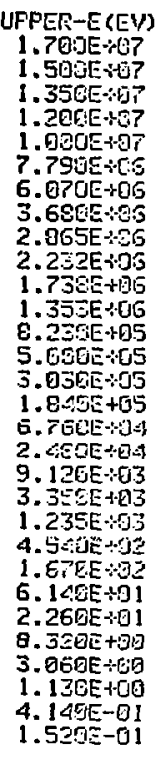 & 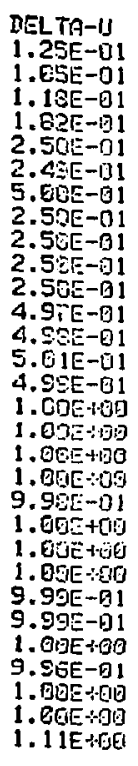 & 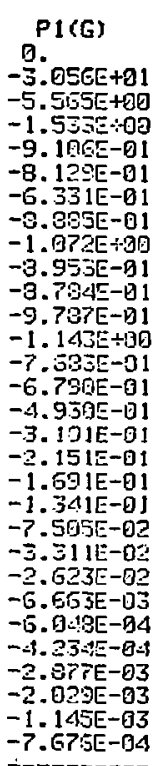 & 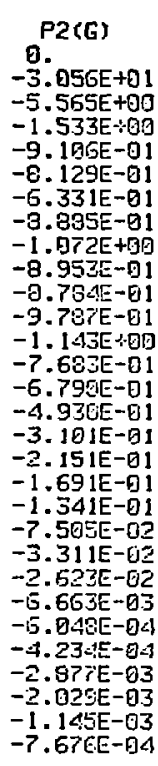 \\
\hline \multicolumn{3}{|c|}{ INTEGRA } & -9 & $E+0$ \\
\hline
\end{tabular}

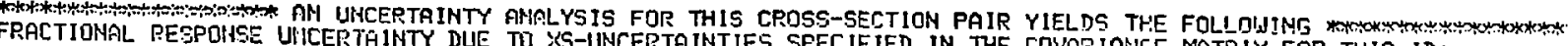
VARIANCE. (DELTA-R OVER R)-SOUARE = (DR/R)SR. = $1.161 E-01$

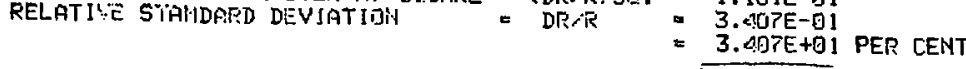




\section{P6(imel, inel)}

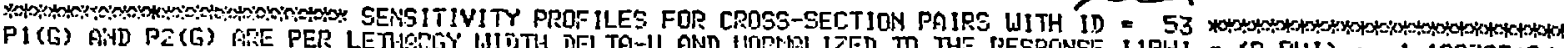
FOR

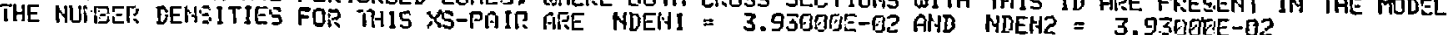

\begin{tabular}{|c|c|c|c|c|}
\hline $\begin{array}{l}\text { POIJP } \\
1 \\
2 \\
3 \\
4 \\
5 \\
6 \\
7 \\
8 \\
9 \\
19 \\
11 \\
12 \\
13 \\
14 \\
15 \\
16 \\
17 \\
19 \\
19 \\
29 \\
21 \\
22 \\
23 \\
24 \\
25 \\
26 \\
27 \\
28 \\
29 \\
30\end{array}$ & 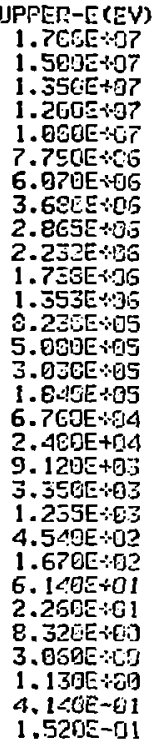 & 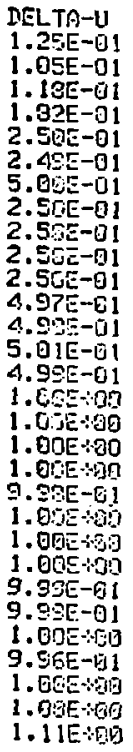 & 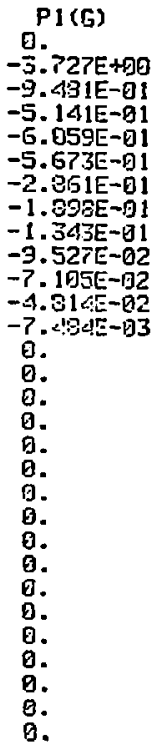 & $\begin{array}{l}\text { P2(G) } \\
9 . \\
-3.727 E+00 \\
-9.491 \mathrm{E}-01 \\
-5.141 \mathrm{E}-01 \\
-6.059 \mathrm{E}-01 \\
-5.673 \mathrm{E}-01 \\
-2.861 \mathrm{E}-01 \\
-1.893 \mathrm{E}-01 \\
-1.343 \mathrm{E}-01 \\
-9.527 \mathrm{E}-02 \\
-7.105 \mathrm{E}-02 \\
-4.914 \mathrm{E}-02 \\
-7.494 \mathrm{E}-0.3 \\
0 . \\
0 . \\
0 . \\
0 . \\
0 . \\
0 . \\
0 . \\
0 . \\
0 . \\
0 . \\
0 . \\
0 . \\
\theta . \\
0 . \\
0 . \\
0 . \\
0 .\end{array}$ \\
\hline \multicolumn{3}{|c|}{ INTEGRA } & & \\
\hline
\end{tabular}

FHA FRACTIONAL RESPOHSE UHCEPTAINTY DUE TO YIS-UNIEERTAINTIES SPECIFIED IN THE COYARIALILE MATRIX FOR THIS ID:

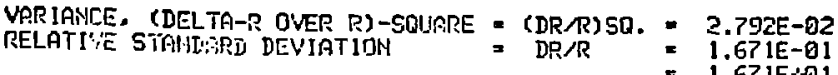

- 1.671E:01 PER CENT 


\section{APPENDIX B}

The following 11 tables are reproduced from the SENSIT printout of our SED uncertainty analysis for those cases where the response uncertainties exceed $10 \%$. The title lines are self expalanatory and the nomenclature coincides with that used in the theory section (Sec. II) of the text. Only for the first case (Cu in $T F+F$ coils for response function $R_{1}$ ) the detailed neutron cross-section and SED sensitivity profiles are also reproduced. The gamma ray sensitivity profiles are all zero for this case because $R_{1}$ is a dpa cross-section which has no gamma ray component. 
TNS (PGFR) XS-SENS. -ANAL. FDR DPA-ADJOINT *TF+E COILS* 156SED: CR,NI,FE(CU)

\begin{tabular}{|c|c|c|c|c|c|c|}
\hline G-IN & $\begin{array}{c}\text { MEDIAN } \\
\text { G-DUT } \\
\text { OF SED } \\
\text { (FROM IHPUT) }\end{array}$ & $\begin{array}{l}\text { INTEGRAL } \\
\text { SED-UHCERT. } \\
\text { F } \\
\text { (FROM INPUT) }\end{array}$ & $\begin{array}{l}\text { HOT INTEGRAL } \\
\text { SEHS. SOEEFF. } \\
\text { S-HOT }\end{array}$ & $\begin{array}{l}\text { COLD IHTESTRAL } \\
\text { SENS. COEFF. } \\
\text { S-COLD }\end{array}$ & $\begin{array}{l}\text { MET INTESRRAL } \\
\text { SED SENS.-COEFF. } \\
\text { S. - } \\
\text { (SHOT - SCOLD) }\end{array}$ & $\begin{array}{c}\text { RESPONSE UNCERT. } \\
\text { DR } / R \\
\text { DUE TD SED-UNCERT. } \\
(F * S)\end{array}$ \\
\hline $\begin{array}{r}1 \\
2 \\
3 \\
4 \\
5 \\
6 \\
7 \\
9 \\
9 \\
9 \\
19 \\
11 \\
12 \\
13 \\
14 \\
15 \\
16 \\
17 \\
18 \\
19 \\
29 \\
21 \\
22 \\
23 \\
24 \\
25 \\
25 \\
27 \\
29 \\
29 \\
3 n\end{array}$ & $\begin{array}{l}8 \\
8 \\
7 \\
4 \\
5 \\
6 \\
6 \\
7 \\
9 \\
9 \\
19 \\
11 \\
12 \\
13 \\
14 \\
15 \\
15 \\
8 \\
8 \\
8 \\
8 \\
9 \\
9 \\
9 \\
9 \\
9 \\
9 \\
9 \\
9 \\
9 \\
9 \\
9 \\
9 \\
9\end{array}$ & 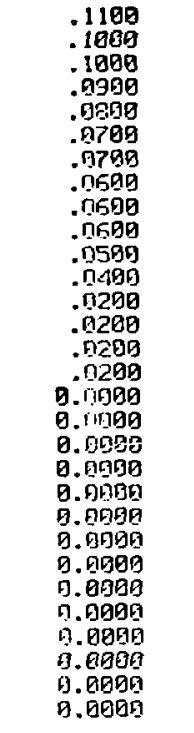 & 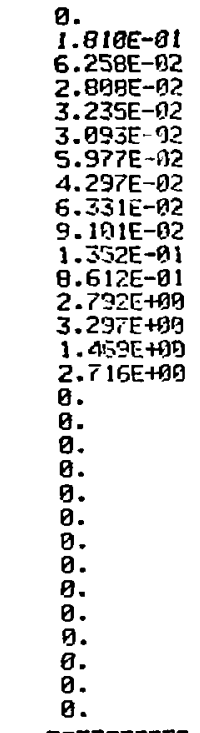 & 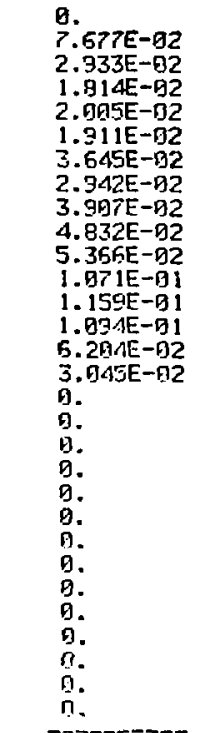 & 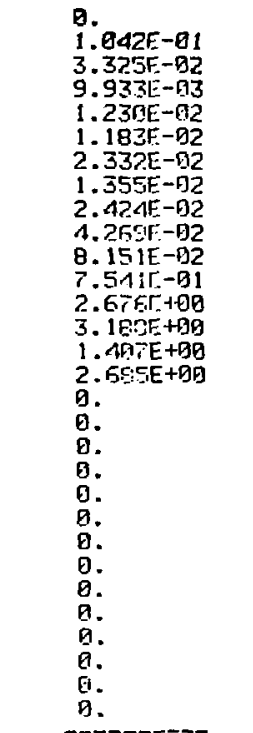 & 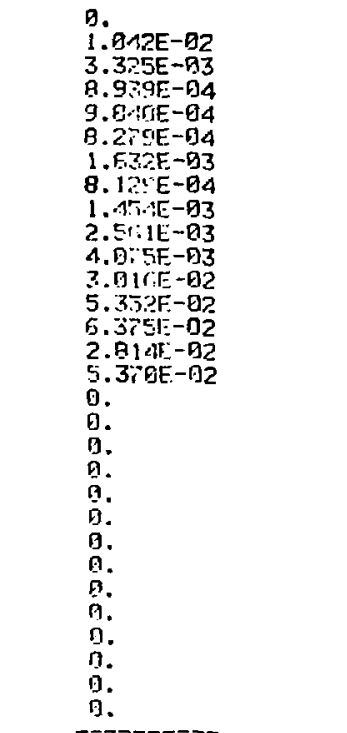 \\
\hline \multicolumn{3}{|l|}{. I } & 1. $186 E+31$ & $7.352 \mathrm{E}-01$ & 1. $19 T E+B 1$ & $\begin{aligned} & 2.5635-91 \\
-25.52 & \text { PER CENT }\end{aligned}$ \\
\hline
\end{tabular}


AXS - SENSITIVITY PROF ILE PER DELTA-U FOR THE AOSORPTION CRDSS-SECTION ITAKEN FROM POSITION IHA IN INPUT CRDSS-SECTION TABLES). PURE LOSS TERM

NU-FISS - SENSITIVITY PROFILE PER DELTR-U FOR THE CROSS SECTION IN POSITION IHA+1 IN INPLT XS-TABLES. WHICH IS USUALLY NU-TIFES THE FISSION CROSS SECTION. PURE LOSS TERM

5Xs

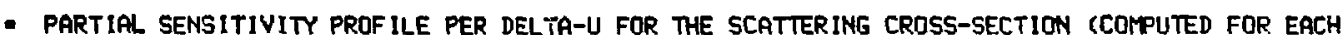
ENERGY GROUP AS A DIAGONAL SUM FROM INPUT XS-TABLES), LOSS TERM ONLY

TXS - SENSITIVITY PROFILE PER DELTA-U FOR THE TOTAL CROSS SECTION (AS GIVEN IN POSITION IHT IN INPUT CROSS-SECTION TABLES). PURE LOSS TERM

N-GAIN - PARTIAL SENSITIVITY PROF ILE PER DELTA-U FOR THE NEUTRON SCATTERIMG CROSS-SECTION. GAIN TERM FOR SENSITIVITY GAINS DUE TO SCATTERING OUT OF ENERGY GROUP G INTO ALL LOLER NEUTRON EMERGY GROUPS. COMPUTED FROM FORIARD D IFFEREHLE FORMULATIOH.

G-GAIN PARTIAL SENSITIVITY PROFILE PER DELTA-U FOR THE GAMTA SCATTERING CROSS-SECTION. GAIH TEPM FOR SENSITIVITY GAINS DUE TO SCATTER ING OUT OF GAMTA ENERGY GROUP G INTO RLL LOWER GAMTIA ENEREY GROUPS, FOR SENSITJVITY GAINS DUE TO SCATTERING OUT OF

N-GAIM(SED) - RE-ORDERED PARTIAL SENSITIVITY PROFILE PER DELTA-U FOR SCATTERING CPOSS-SECTION. GAIN TERM FOR SENSITIVITY GAINS DUE TI SCATTERING INTO GROUP G FROM ALL HIGHER NEIJTRON ENERGY TIROUPS, COMFUTED FROM ADJOINT D IFFERNCE FORMULRTION.
CORRESPONDS TO SJNGLE-D IFFERENTIAL SED SENSITIVITY PROF ILE, PSED (G-OUT) PER DELU-JUT. INTEGRATED OVER ALL INC IDENT ENERGY GRDUPS.

NG-GAIN - PARTIAL SENSITIVITY PROFILE PER DELTA-U FOR THE GAMMA PRODUCTION CROSS-SECTIOH

PARTIAL SENSITIVITY PROF ILE PER DELTA-UU FOR THE GAMM PRODUCTION CROSS-SECTION GROUP G INTO ALL GATMA GPOUPS.

SEN - NET SENSITIVITY PRDFILE FER DELTA-U FOR THE SCATTERIMG CROSS-SECTION (SEN=SXSHEAIN)

SENT - NET SENSITIVITY PROFILE PER DELTA-U FOR THE TOTAL CRN55-SECTION (SENTETXS+NGAIN)

SEMR - SENSITIVITY PROFILE PER DELTA-U FOR THE DETECTOR RESPDNSE FUNCTION R(G)

SENO - SENSITIVITY PROFILE PER DELTA-UJ FOR THE SOURCE DISTRIBUTION FUNCTION O(G) 
旁喜

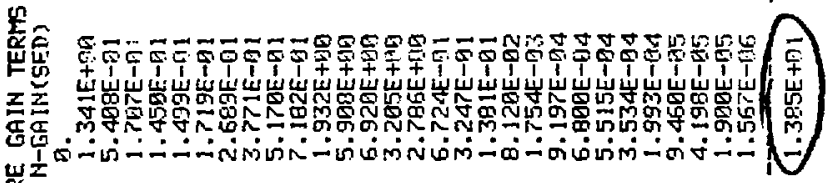
岸

ว

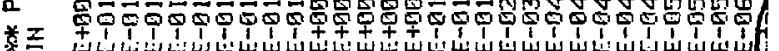
委索

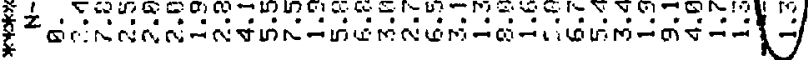

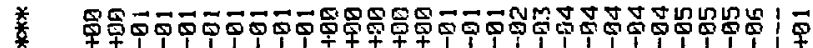
/

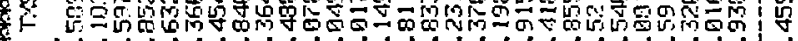

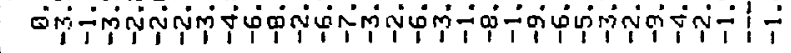

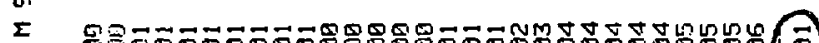

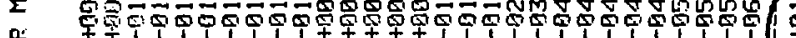

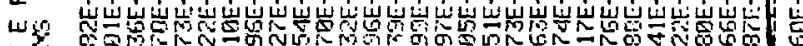

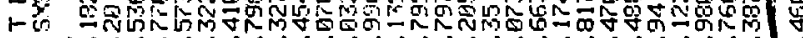

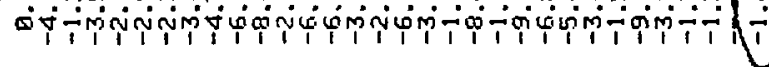
a C. ய n. 2

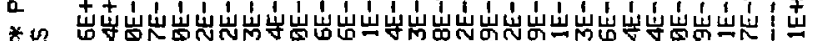

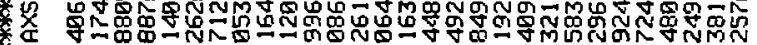

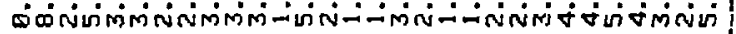

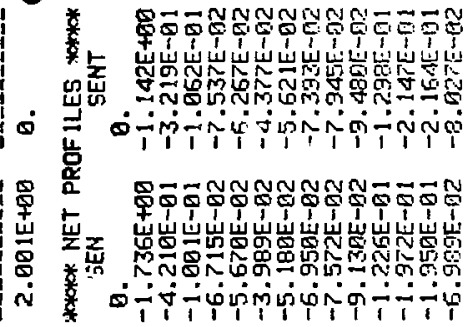

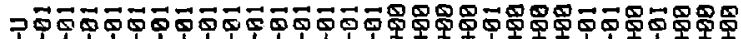

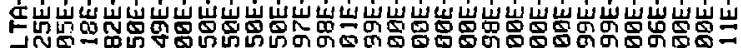
मํ.

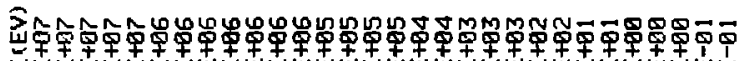

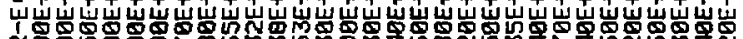

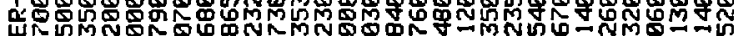

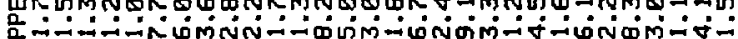
S-ーーーーA

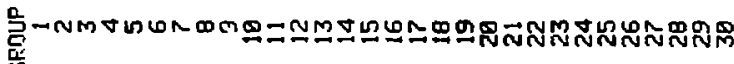

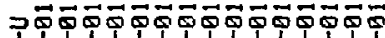

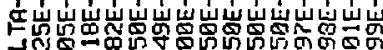

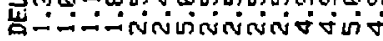

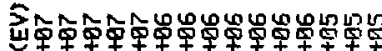

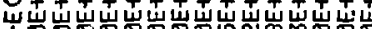

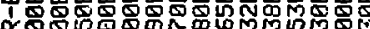

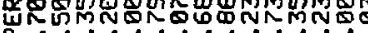

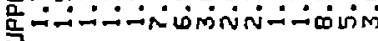

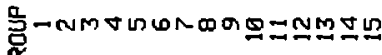




\begin{tabular}{|c|c|c|c|c|}
\hline $\begin{array}{l}16 \\
17 \\
19 \\
19 \\
29 \\
21 \\
22 \\
23 \\
24 \\
25\end{array}$ & 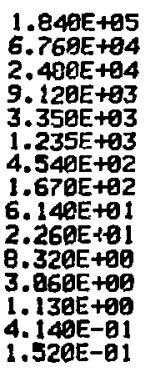 & 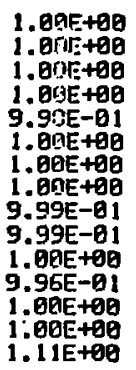 & $\begin{array}{r}-5.6396-02 \\
-2.020 E-92 \\
-9.258 E-83 \\
-8.526 E-84 \\
-6.466 E-84 \\
-1.320 E-95 \\
-1.118 E-85 \\
-2.229 E-96 \\
-1.086 E-96 \\
-9.321 E-97 \\
3.661 E-97 \\
6.374 E-97 \\
6.576 E-97 \\
-4.462 E-97 \\
-3.194 E-98\end{array}$ & $\begin{array}{l}-6.823 E-02 \\
-2.3 A F E-02 \\
-1.195 E-02 \\
-2.797 E-93 \\
-1.89 A E-93 \\
-2.656 E-64 \\
-3.551 E-85 \\
-5.954 E-66 \\
-5.591 E-66 \\
-5.993 E-86 \\
-5.633 E-96 \\
-4.058 E-96 \\
-2.737 E-96 \\
-2.942 E-96 \\
-5.620 E-07\end{array}$ \\
\hline \multicolumn{3}{|l|}{ INTECS } & & \\
\hline
\end{tabular}




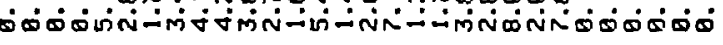

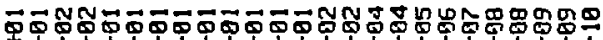

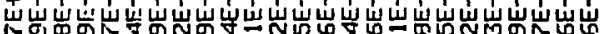

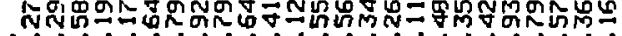
क-

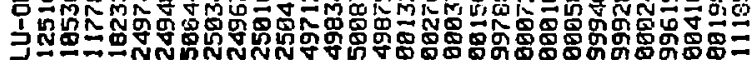

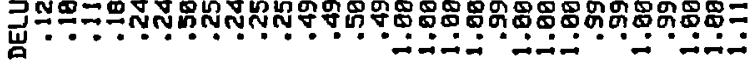
吉

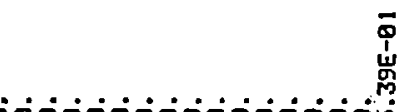

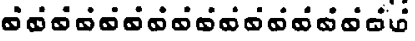

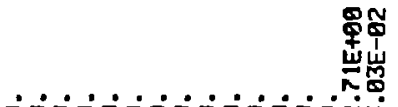

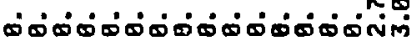<smiles>C1C2C[As]1[Se]2</smiles>

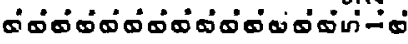<smiles></smiles>

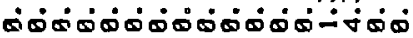

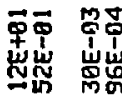

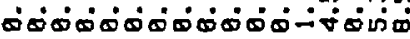

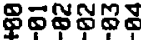

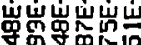

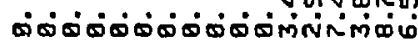

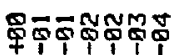

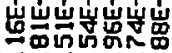

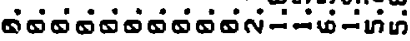

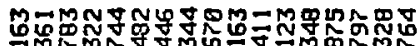

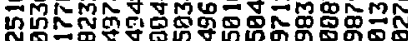

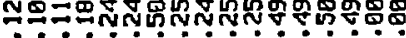

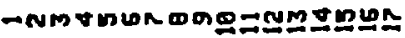




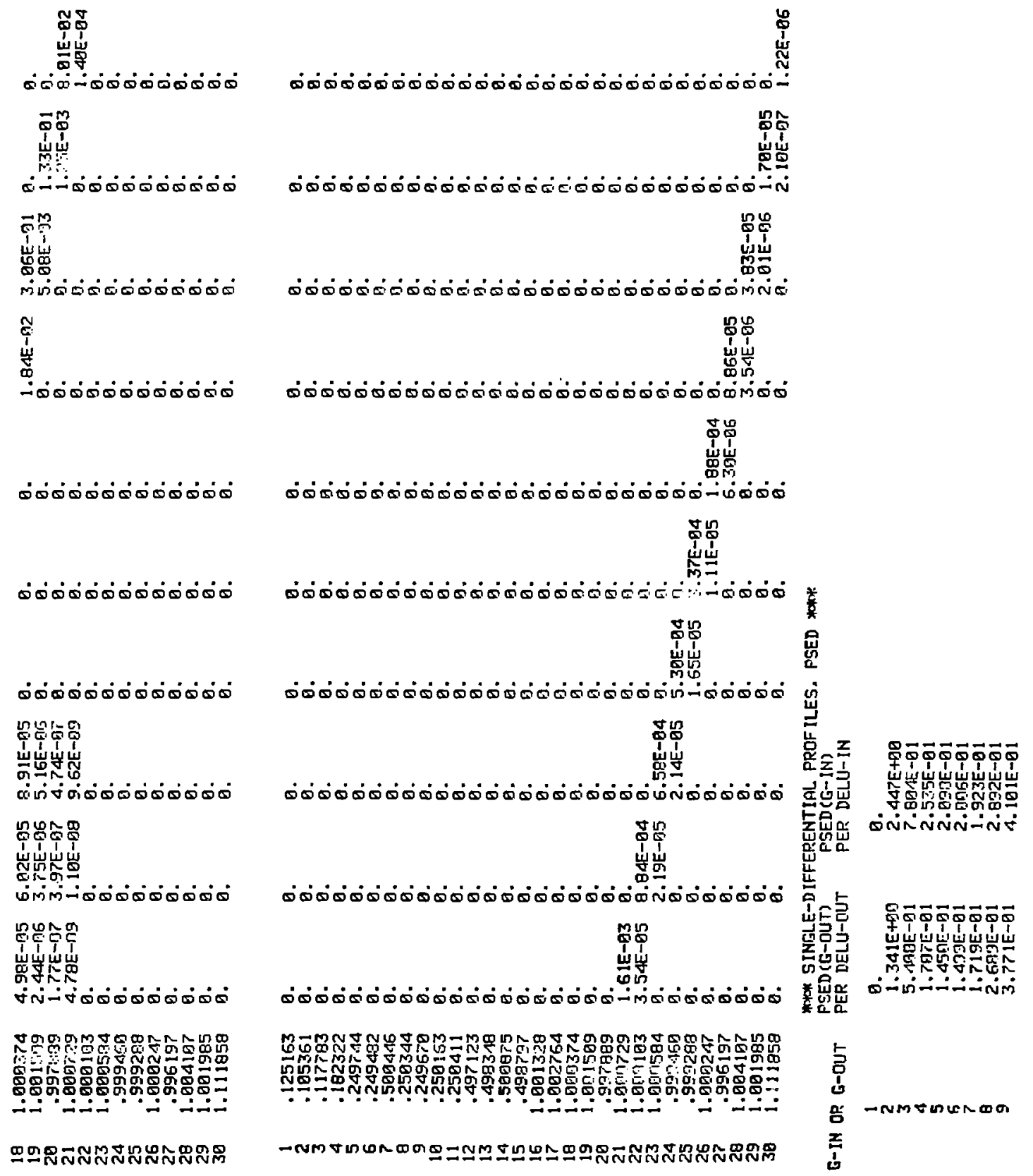




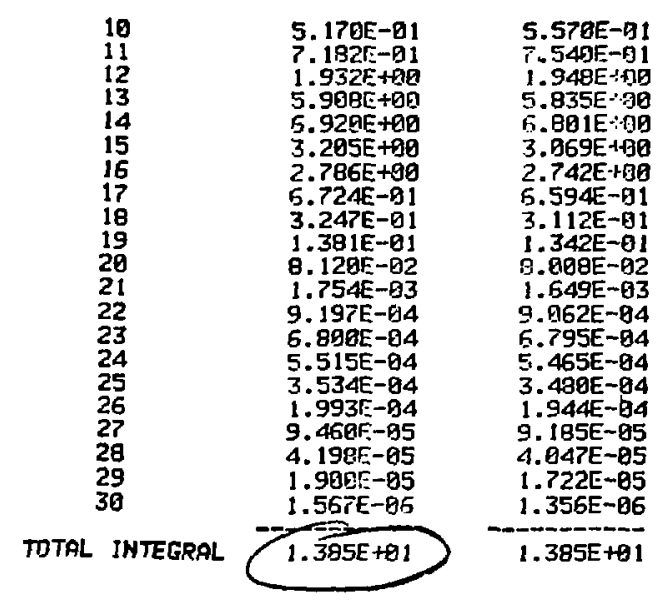


TNS(PGFR) XS-SENS.-ANALYSIS FDR DPA-ADJOINT * SHIELD * ISSSED: H.Q.W

\begin{tabular}{|c|c|c|c|c|c|c|}
\hline G-I & $\begin{array}{c}\text { MEDIAM } \\
\text { G-OUT } \\
\text { OF SED } \\
\text { (FRDM INPUT) }\end{array}$ & $\begin{array}{l}\text { INTEGRAL } \\
\text { SED-UNCERT. } \\
\text { F } \\
\text { (FROM INPUT) }\end{array}$ & $\begin{array}{c}\text { HOT INTEGRAL } \\
\text { SENS. CDEFF. } \\
\text { S-HOT }\end{array}$ & $\begin{array}{l}\text { COLD INTEGRAL } \\
\text { SENS. COEFF. } \\
\text { S-CDLD }\end{array}$ & $\begin{array}{l}\text { NET INTEGRAL } \\
\text { SED SENS.-COEFF. } \\
S \text { - } \\
\text { (SHOT }- \text { SCOLD) }\end{array}$ & $\begin{array}{c}\text { RESPONSE UNCERT. } \\
\text { DPR R } \\
\text { DUE TU SED-UNCERT. } \\
(F * 5)\end{array}$ \\
\hline $\begin{array}{r}1 \\
2 \\
3 \\
4 \\
5 \\
6 \\
7 \\
日 \\
9 \\
10 \\
11 \\
12 \\
13 \\
14 \\
15 \\
16 \\
17 \\
18 \\
19 \\
20 \\
21 \\
22 \\
23 \\
24 \\
25 \\
26 \\
27 \\
28 \\
29 \\
30\end{array}$ & $\begin{array}{r}10 \\
19 \\
19 \\
11 \\
12 \\
6 \\
7 \\
8 \\
9 \\
19 \\
11 \\
12 \\
13 \\
14 \\
15 \\
16 \\
0 \\
0 \\
0 \\
0 \\
0 \\
0 \\
0 \\
0 \\
0 \\
9 \\
0 \\
0 \\
6 \\
0\end{array}$ & 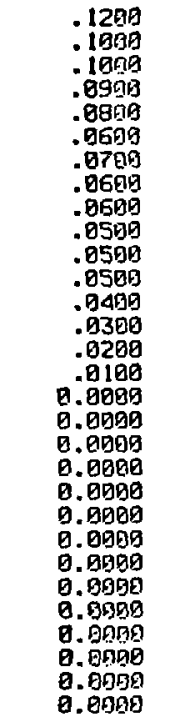 & 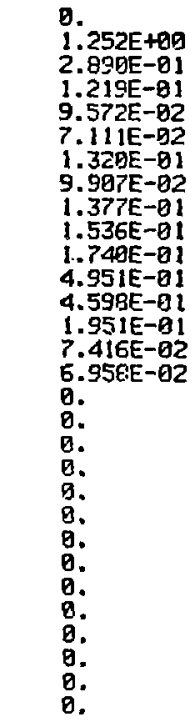 & $\begin{array}{l}9 . \\
1.257 \mathrm{E}-01 \\
3.061 \mathrm{E}-02 \\
1.629 \mathrm{E}-02 \\
6.247 \mathrm{E}-03 \\
2.197 \mathrm{E}-92 \\
3.368 \mathrm{E}-02 \\
2.593 \mathrm{E}-92 \\
3.586 \mathrm{E}-02 \\
3.951 \mathrm{E}-02 \\
3.584 \mathrm{E}-02 \\
4.560 \mathrm{E}-02 \\
2.531 \mathrm{E}-02 \\
9.969 \mathrm{E}-03 \\
3.036 \mathrm{E}-03 \\
3.665 \mathrm{E}-04 \\
0 . \\
0 . \\
0 . \\
0 . \\
0 . \\
0 . \\
0 . \\
0 . \\
0 . \\
0 . \\
9 . \\
9 . \\
9 . \\
9 .\end{array}$ & 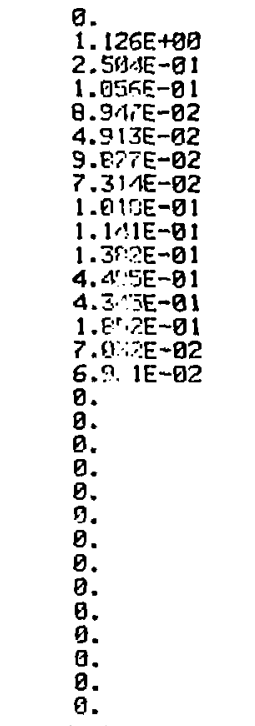 & 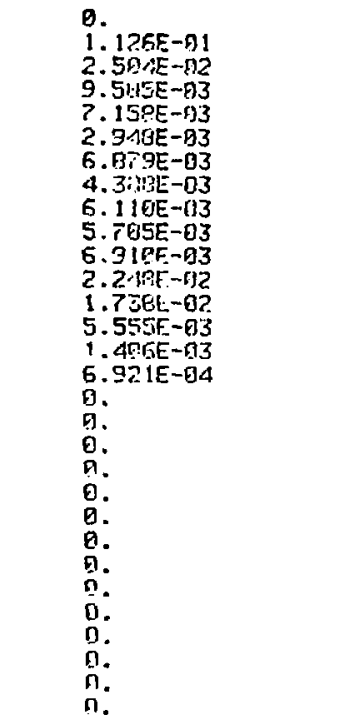 \\
\hline \multicolumn{3}{|c|}{ TOTAL INTEGRAL } & $3.820 \mathrm{E}+\mathrm{HO}$ & $4.647 \mathrm{E}-91$ & $3.355 \mathrm{E}+00$ & $\begin{array}{r}2.348 E-01 \\
23.473 \text { PER CENT }\end{array}$ \\
\hline
\end{tabular}


TNS (PGFR) XS-SENS. -ANALYSIS FOR AL-DPA-ADJ. F-COIL * 164SED (CU)

\begin{tabular}{|c|c|c|c|c|c|c|}
\hline G-II & $\begin{array}{c}\text { MEDIAN } \\
\text { G-DUT } \\
\text { OF SED } \\
\text { (FROM INPUT) }\end{array}$ & $\begin{array}{c}\text { INTEGERL } \\
\text { SED-UNCERT. } \\
\text { F } \\
\text { (FROM INPUT) }\end{array}$ & $\begin{array}{l}\text { HOT INTEGPAL } \\
\text { SENS. COEFF. } \\
\text { S-HOT }\end{array}$ & $\begin{array}{l}\text { COLD INTEGRAL } \\
\text { SENS. CDEFF. } \\
\text { S-COLD }\end{array}$ & $\begin{array}{c}\text { NET INTEGRAL } \\
\text { SED SF,NS, -CDEFF. } \\
\text { S }- \text { SCOLD }\end{array}$ & $\begin{array}{c}\text { RESPONSE LUNCERT. } \\
\text { DR/R L-UNCERT. } \\
\text { DUE TO SED-UNCERT. } \\
(\mathrm{F} * S)\end{array}$ \\
\hline $\begin{array}{r}1 \\
2 \\
3 \\
4 \\
5 \\
6 \\
7 \\
8 \\
9 \\
19 \\
11 \\
12 \\
13 \\
14 \\
15 \\
16 \\
17 \\
18 \\
19 \\
20 \\
21 \\
22 \\
23 \\
24 \\
25 \\
26 \\
27 \\
28 \\
29 \\
30\end{array}$ & 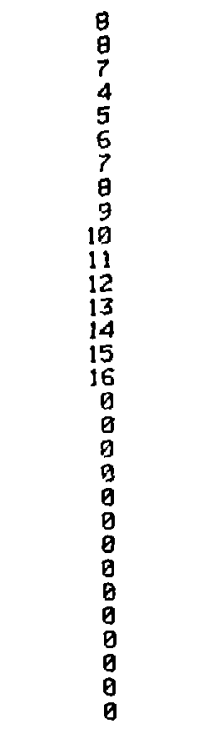 & 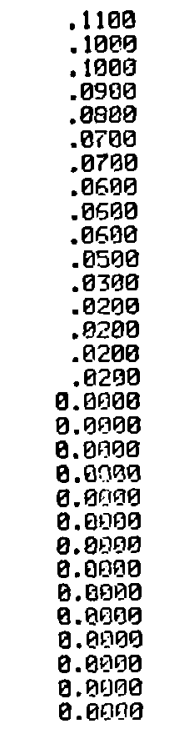 & 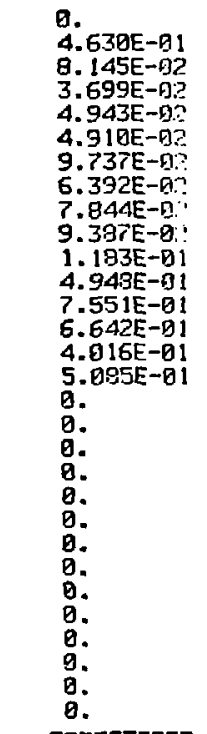 & 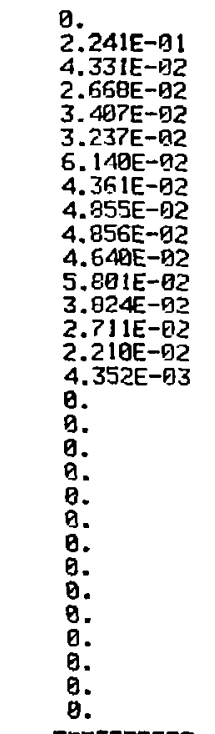 & 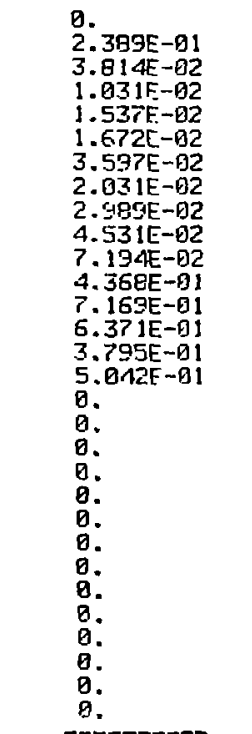 & 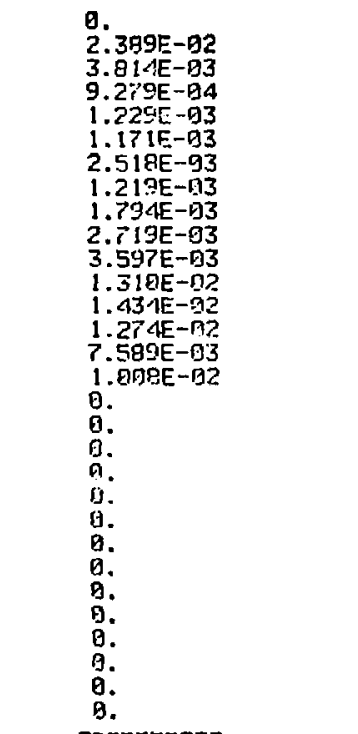 \\
\hline \multicolumn{3}{|c|}{ TOTAL INTEGRAL } & $3.956 E+98$ & $7.588 E-01$ & $3.197 E+98$ & $\begin{array}{l}\text { 1. BDFE-Q1 } \\
10.07 . A \text { PER CENT }\end{array}$ \\
\hline
\end{tabular}




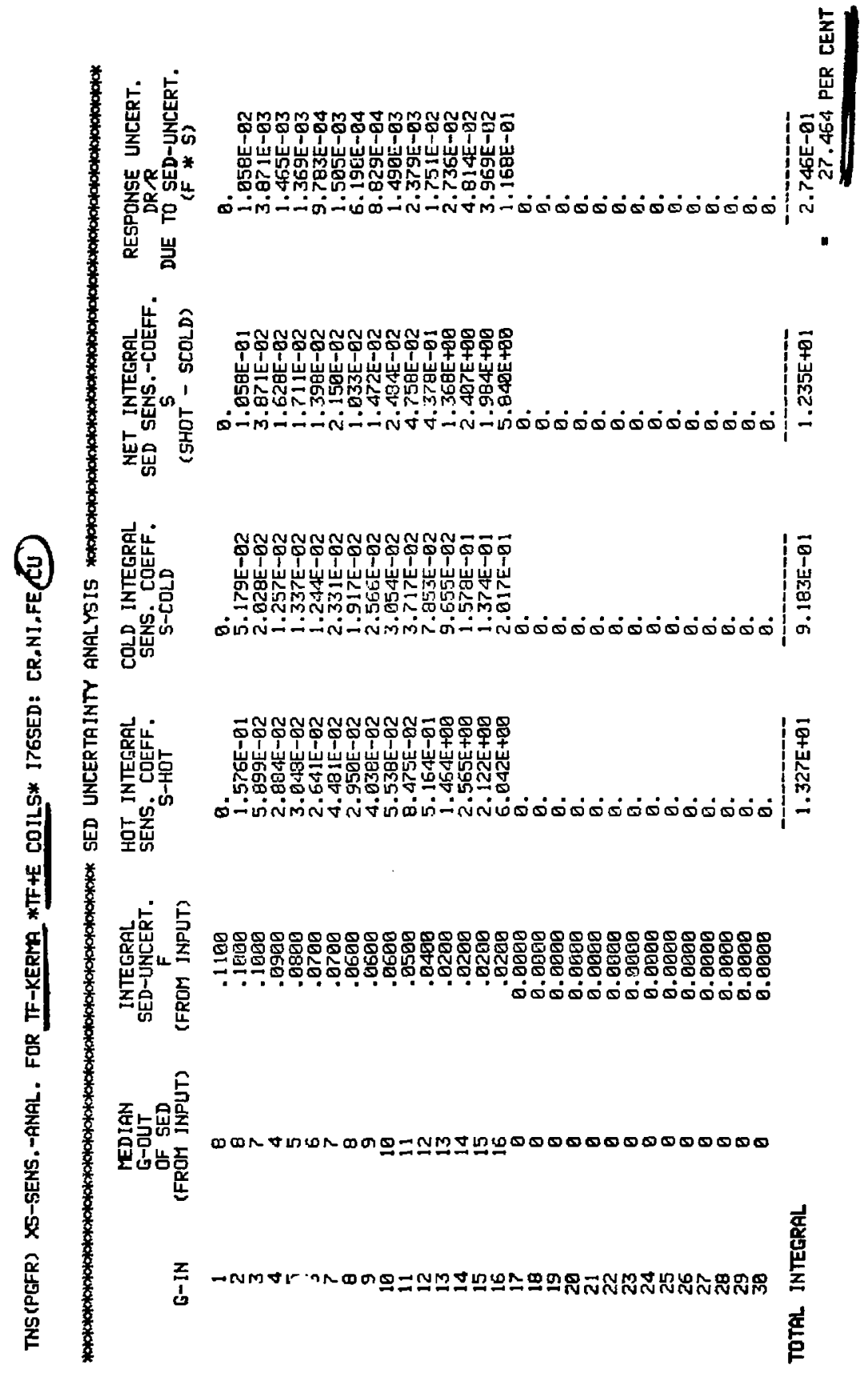




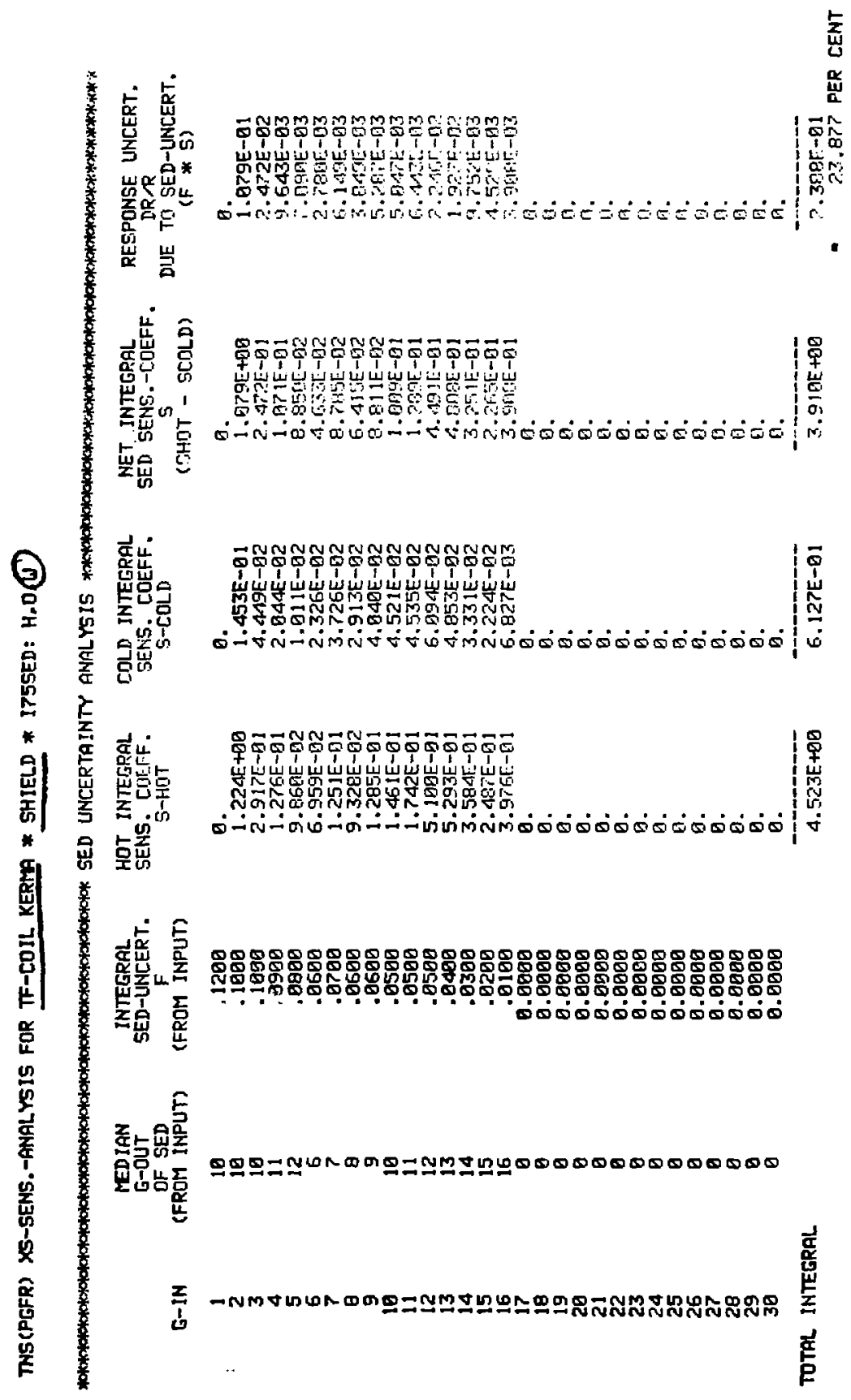

